\title{
نسب مساهمة الذكاءات المتعددة فى تفوق الطالبة المعلمة
}

\section{"د / نيفيز أسعد يوسف الطفه}

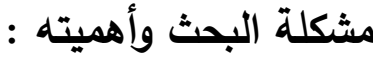

يعد الذكاء من أكثر المفاهيم التى نالت إهتمام علماء النفس منذ بداية

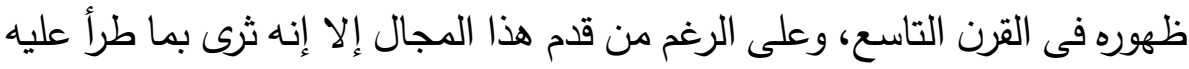

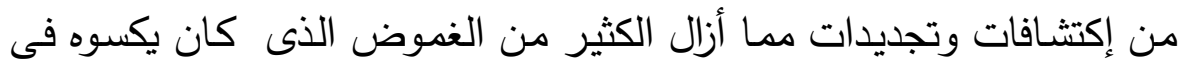
الماضى، فقد توصلت جهود الباحثين الى التعرف على طبيعة الذكاء وتحديد ما آليان إذا كان مكونا من قدرة عقلية عامة أو مجموعة من القدرات المستقلة.

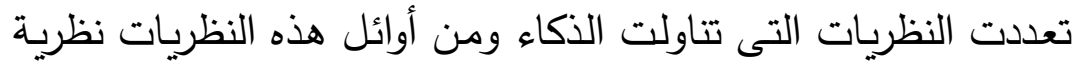

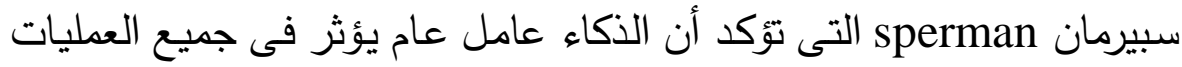
العقلية بنسب متفاوته، ثم ظهرت نظريـة العوامل المتعددة (لثورنديك التيك الذى رفض فكرة وجود عامل عام وفسر الذكاء على انه يتكون (thorandick

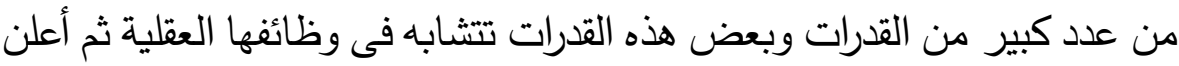
أن هنالك ثلاث أنواع من الذكاء هي الذكاء الذاء الدجرد، الذكاء الاجتماعى، الذكاء

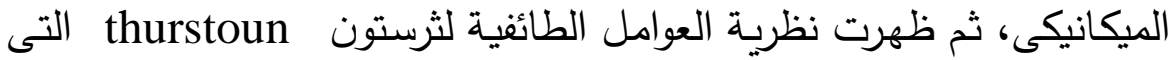

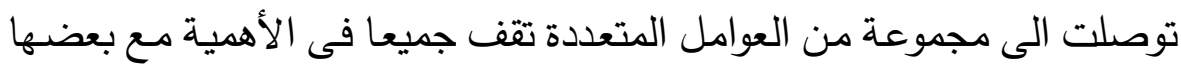

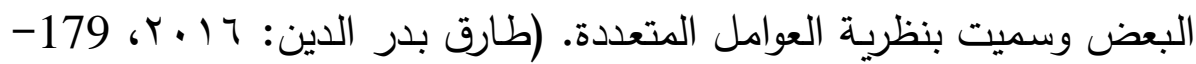

(183

أما "جاردنر gardner" فقد أسقط هذه المفاهيم عندما أسس نظريـة

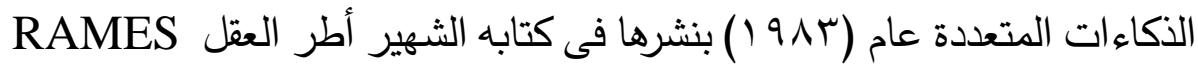

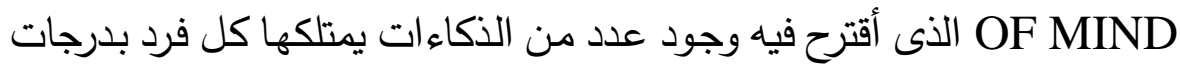

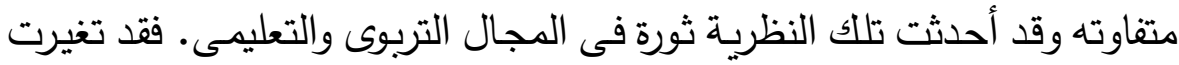

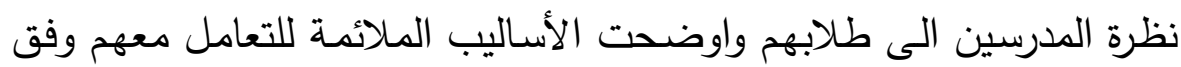

" أستاذ مسـاعد بقسم العلوم التربويه والنفسيه والاجتماعيه، كلية التربيه الرياضيه للبنات،

\section{مجلة أسيوط لعلوم وفنون التربية الرياضية}

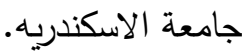


قدراتهم الذهنية، كما شكلت هذه النظريـة تحديا للمفهوم التقليدى للذكاء على إنه

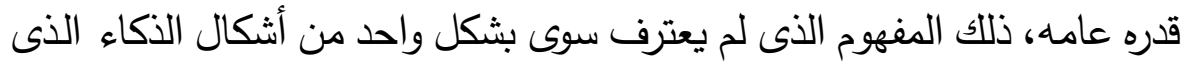
يظل ثابتا لدى الفرد فى مختلف مراحل حياته، حيث أشارت نظريـة الذكاءات الى الى لى الإختلاف بين الناس فى أنواع الذكاءات التى لديهم وفى أسلوب إستخدامها، وأن كل الأفراد لايهر عدة ذكاءات ولا يمتلكون نفس المقدرة ولا نفس الكمية منه.

$$
\text { ( } \varepsilon-r \text { ، 1997:Checkley) }
$$

وبإستكشـاف هذه الذكاءات وتتشيطها وجعلها المـدخل التعليمي للفرد

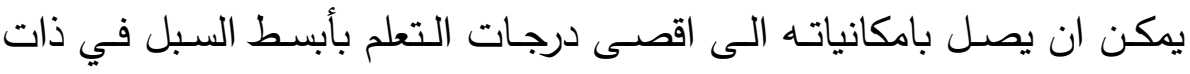

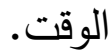

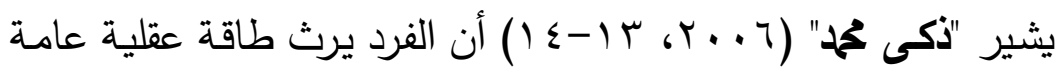

تتمايز فيما بعد الى قدرات عقلية خاصة بفعل الظروف البيئية المحيطة. فإن ورث

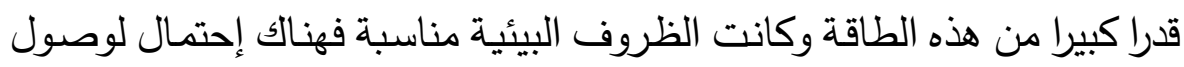
هذا الفرد الى مستوى آداء مرتفع فى المجال الذى وجهت اليه هذه الطاقة.

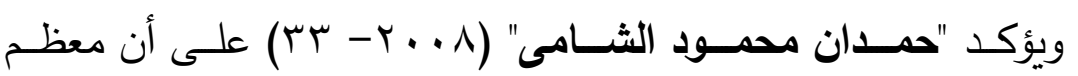

الأنشطة الحياتيه تتطلب تجميع عدد من الذكاءات المتعددة الموجودة لدى كل

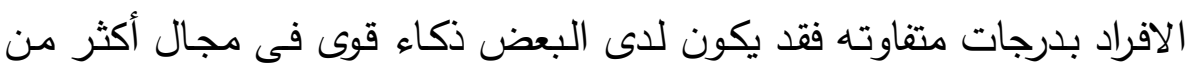

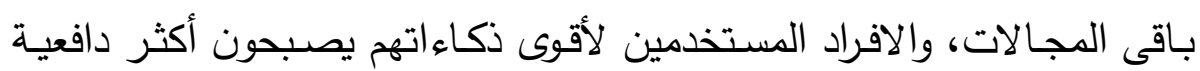

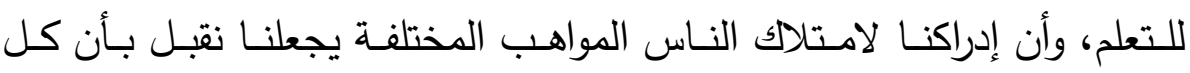
شخص لديه شئ قيم يعرضه، وكلنا نمتلك القدرة التى تمكننا من تزويد مواهبنا الضعيفة.

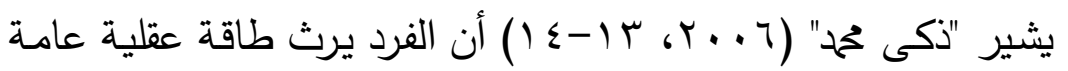
تتمايز فيما بعد الى قدرات عقلية خاصة بفعل الظروف البيئية المحيطة. فإن ورث قدرا كبيرا من هذه الطاقة وكانت الظروف البيئية مناسبة فهناك إحتمال لوصسول هذا الفرد الى مستوى آداء مرتفع فى المجال الذى وجهت اليه هذه الطاقة. 


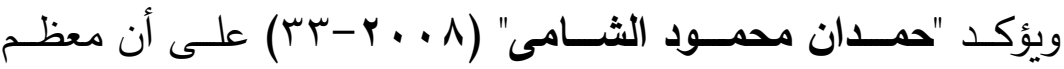

الأنشطة الحياتيه تتطلب تجميع عدد من الذكاءات المتعددة الموجودة لدى كل الأفراد بدرجات متفاوته فقد يكون لدى البعض ذكاء قوى فى مجال أكثر من باقى المجالات، والافراد المستخدمين لأقوى ذكاءاتهم يصسبحون أكثر دافعية

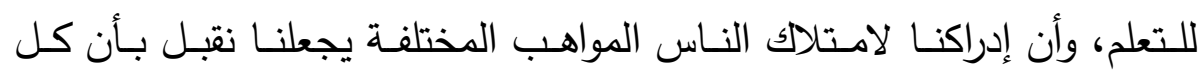
شخص لديه شئ قيم يعرضه، وكلنا نمتلك القدرة التى تمكننا من تزويد مواهبنا

الضعيفة.

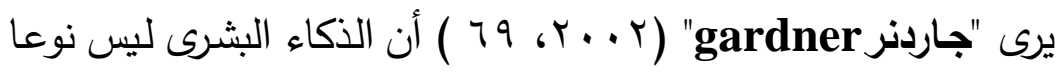
واحدا كما هو متعارف عليه وإنما ينقسم الذكاء الانسـانى الى مجموعة من الذكاءات المختلفة والمجتمعة فى الفرد الواحد بدرجات متفاوته، وهذه الدرجات هى التى تحدد مدى تفوق هذا الفرد فى مجال معين، وبالتالى فإن إستكشاف هذا

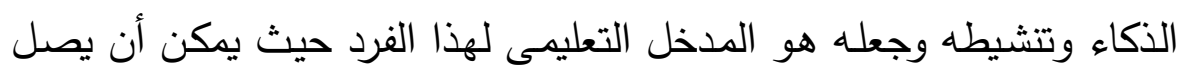
بإمكانياته الى أقصى درجات التعلم بأبسط السبل فى ذات الوقت. فالاقراد يختلفون من حيث أنواع الذكاءات التى يمتلكونها الأمر الذى يفتح دئح المجال أمام المربين لكسر النظرة الموحدة للتعلم واستثمار القدرات العقلية والمعرفيه التى يمتلكها المتعلمين والعمل على رعايتها، ووفقا لنظريـة جاردنر gardner

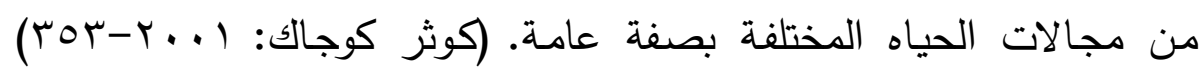

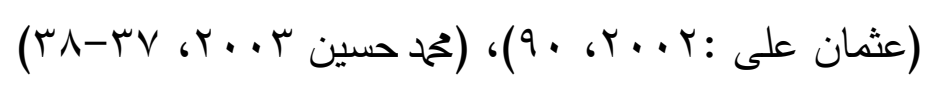

وتعد نظريـة جاردنر للذكاءات المتعددة أفضل وأقوى نظريـة معرفية الفية

ظهرت حتى الآن، فهى بمثابة نموذج معرفى يحاول أن يصف كيف يستخدم

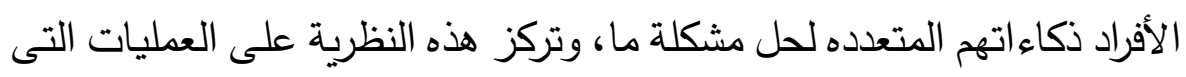

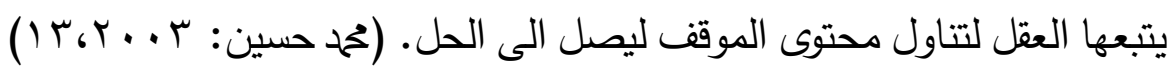


كما غيرت نظريـة الذكاءات المتعددة النظرة السائدة عن مفهوم الذكاء حيث أشارت الى أن النجاح فى الحياه يتطلب ذكاءات متنوعة، وأن أهم ما يجب أن يقدمه المعلم للطالب هو توجيهه نحو المجالات التى تتناسب مع أوجه الكفاءة

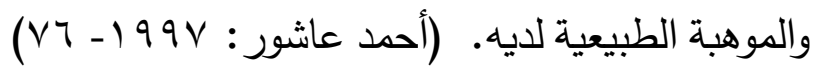
وقد أصبحت هذه النظرية محل إهتمام الباحثين لما لها من دور هام فى التى عملية التعلم بوجه عام وزيادة التحصيل الدراسى على وجه الخصوص، وترجع الأهمية التربوية لنظرية الذكاءات المتعددة فى انها تحاول وصفيه ولئ كيف يستخدم

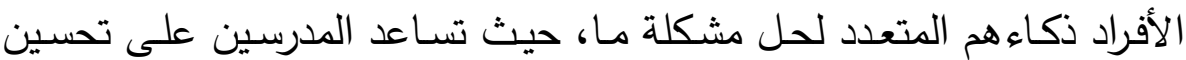
آدائهم فى عملية التعليم، كما تراعى طبيعة وميول المتعلمين وتعمل على تتمية

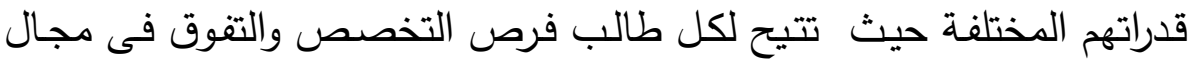
واحد مما يضاعف فرص الفهم والإحتفاظ بالمعلومات وبالتالى النجاح والتفوق.

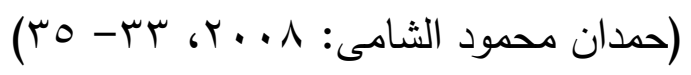

لذلك يجب على القائمين بالتدريس ومعدى المناهج الدراسية مراعاة التتوع

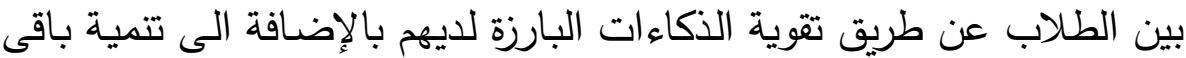

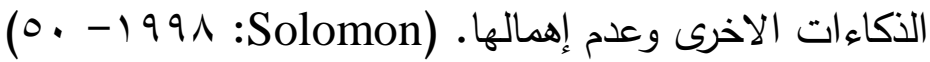
فكل طالب لايه مجموعـه من القدرات الفريدة، ومهمة المعلم التعرف على التهي

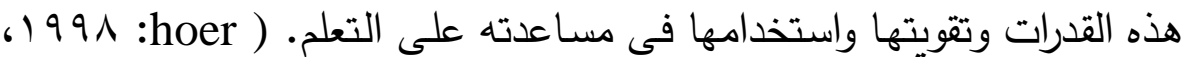

وترى الباحثه ان كليات التربيه الرياضيه تواجه تحديات كبيرة لمسايرة

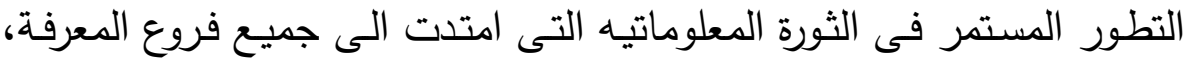

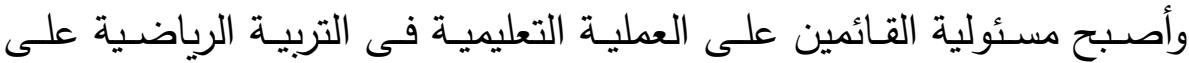

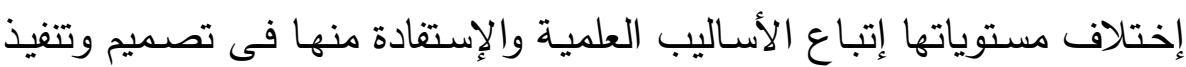

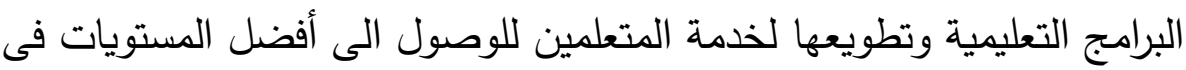
التحصيل المعرفى والآداء.

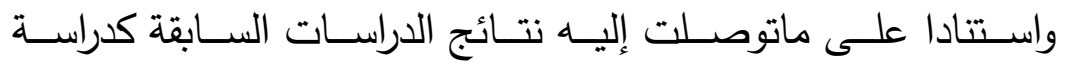

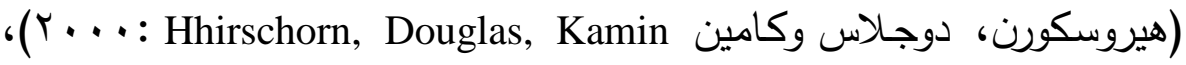

\section{مجلة أسيوط لعلوم وفنون التربية الرياضية}


Mcmahon.s.d \& Rose.d دراسة (ماكماهون. س.د، روز. د. س)

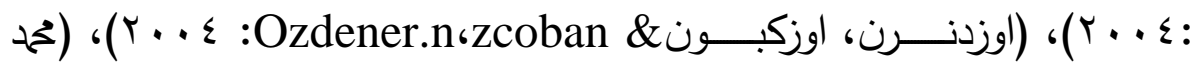

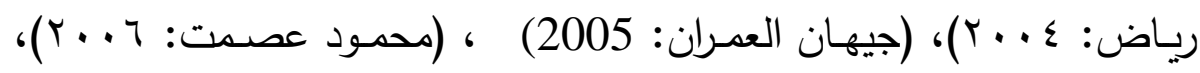

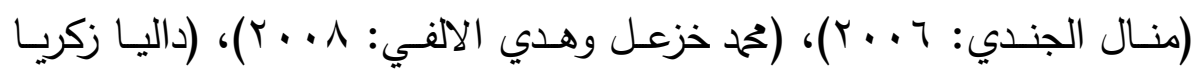

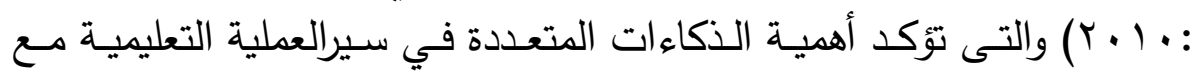
مراعاة ان الذكاء ليس قدرة عامـة ولكن ذكاءات متعددة يمكن الاسترشاد بها وتفعيلها.

وترى الباحثة أن الطالبـات فـى كليـة التربيـة الرياضية تقدـن باختيـار

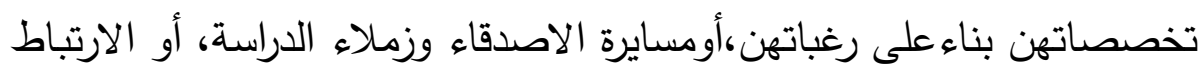

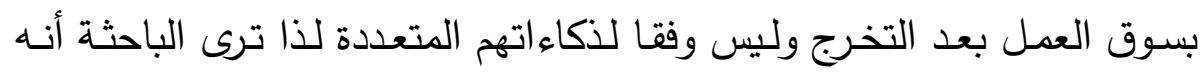

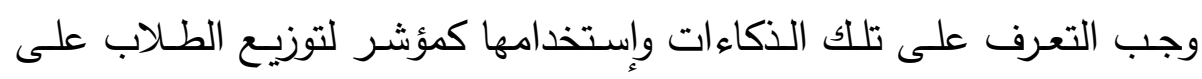

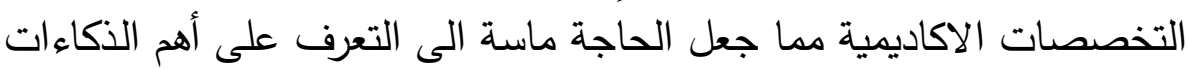

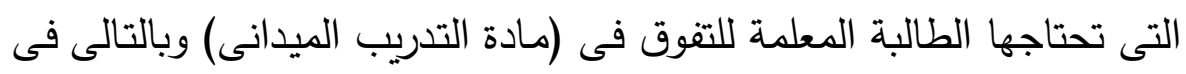
التدريس.

وهذا ما دعى الباحثة الى إجراء الدراسه الحاليه بهدف التعرف على التى

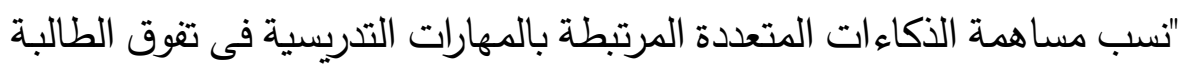

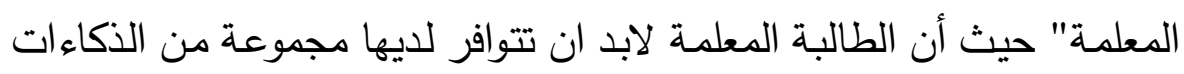

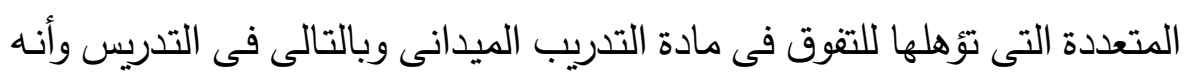

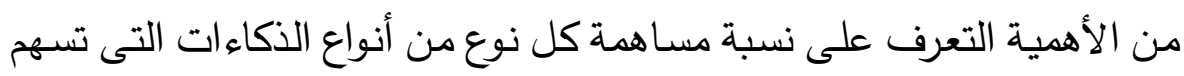

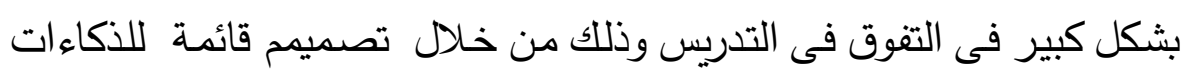

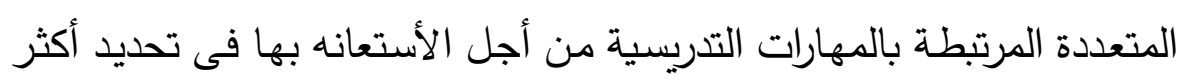
الذكاءات التى تحتاجها الطالبة المعلمة.

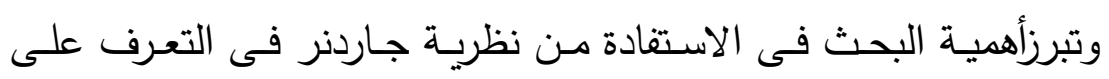

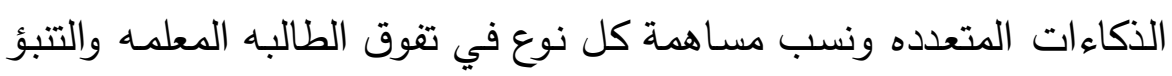
بدرجة الطالبة فى مادة التدريب الميدانى بمعلومية الذكاءات المتعددة. 
كما تفيد نتائج الدراسة الحالية المسئولين وأصحاب القرار فى العمل على تطوير الذكاءات المتعدده المرتبطة بالمهارات التدريسية التى تحتاجها الطالبة، وهذا ما دعى الباحثة الى إجراء هذا البحث بعنوان "نسب مساهمة الذكاءات المتعددة فى تفوق الطالبة المعلمة".

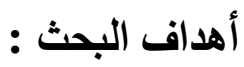
يهدف البحث الى التعرف على :

1- الذكاءات المتعددة المسهمه في تفوق الطالبة المعلمة. r- نسب مساهمة الذكاءات المتعددة فى تفوق الطالبة المعلمة فى مادة التدريب الميدانى.

r- التنبؤ بدرجة الطالبة المعلمة فى مادة التدريب الميدانى بمعلومية الذكاءات المتعددة.

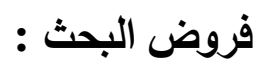
1- تسـهم الذكاءات المتعددة بنسب متباينة في تفوق الطالبة المعلمة فى مادة

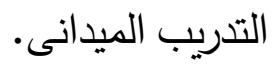
r- يمكن التتبؤ بدرجة الطالبة المعلمة فى مادة التدريب الميدانى بمعلومية الأكاءات المتعددة لديها. : مصطات البحث - الأكاءات المتعددة :

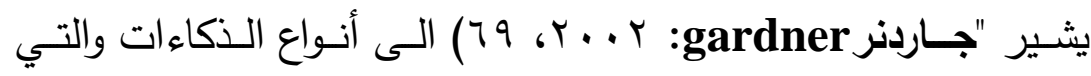

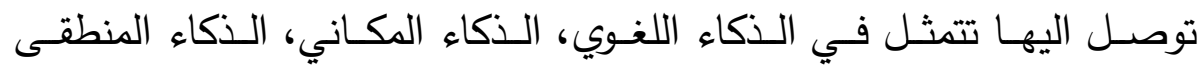
الحسابى، الذكاء الجسمي الحركى، الذكاء الموسيقي، الذكاء الاجتماعي، الذكاء الشخصي. - التفوق في مادة التدريب الميداني :

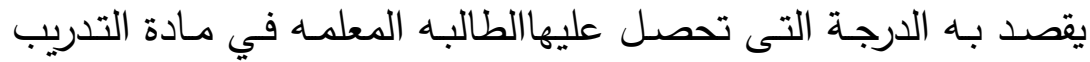

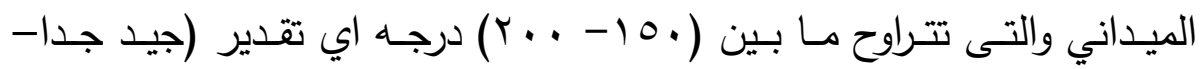
امتياز) ) (تعريف اجرائي) 


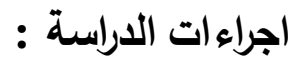

منهج الدراسة :

تم إستخدام المنهج الوصفى بالإسلوب المسحى لملاءمته لطبيعه وأهداف

$$
\text { عينة الدراسةة. }
$$

تم إختيار عينة الدراسـة بالطريقة العمدية واشتمل على جميع طالبات الفرقة الرابعة (شعبة تعليم) بكلية التربية الرياضية للبنات - جامعة الأسكندرية

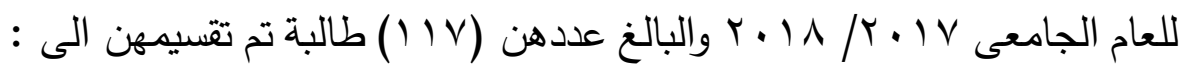
عينة الدراسة الاستطلاعية : لإعي اشتملت على (·r) طالبه تم اختيـارهن بطريقـه عشوائيه مـن مجتمـع البحث بهدف تقنين قائمة الذكاءات المتعدده. عينة الدراسة الأساسية : اشتملت على (Av) طالبه تم تقسيمهن وفقا لدرجاتهن في مادة التدريب
الميداني كما يوضحها جدول (1)

جدول (1)

\begin{tabular}{|c|c|c|c|}
\hline \multirow{2}{*}{ الطالبات } & \multicolumn{2}{|c|}{ الدرجه } & \multirow{2}{*}{ التقديـر } \\
\hline & S11 & jo & \\
\hline 0 & 1199 & $1 \ldots$ & مقبول \\
\hline Ir & $1 \leqslant 9$ & $1 \pi$. & جيد \\
\hline$\varepsilon r$ & 179 & 10. & جيد جدا \\
\hline$T V$ & Y... & IV. & مثتاز \\
\hline$\Lambda V$ & \multicolumn{3}{|c|}{ العدد الكلى لعينة الدراسه الاساسيه } \\
\hline
\end{tabular}

توصيف عينة الاراسه الاساسيه وفقا لارجاتهن في مادة التدربب الميداني

تم ترتيب درجات طالبات عينة الدراسه الاساسيه في مادة التدريب

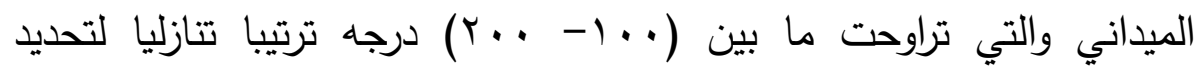
الطالبات المتقوقات الحاصلات على تقدير جيد جداكممتاز وعددهن (V•) طالبه واستبعاد (IV) طالبه واللاتي لا تتطبق عليهن شروط التقوق في مادة التدريب الميداني 
أ- قائمة الذكاءات المتعددة للطالبة المعلمة (إعداد الباحثة) .

ب- بطاقة ملاحظة لتقييم الكفاءة التدريسية للطالبة المعلمة. أ- قائمة الأكاءات المتعددة للطالبة المعلمة (إعداد الباحثة)

خطوات اعداد قائمة الأكاءات المتعددة للطالبة المعلمة :

1 - تحديد الأبعاد الاساسية لقائمة الأكاءات المتعددة للطالبة المعلمة: من خلال المسح المرجعى تم حصر الدراسات العربية والأجنبية التي تناولت الأكاء ات المتعددة وهي : j.ivanco قائمة الذكاءات المتعددة اعداد) ايفانكو : 1998 -

Niall Dauglas (2002: قائمة الذكاءات المتعددة اعداد ) - نيال دوجلاس - Andrea Nagni قائمة الذكاءات المتعددة اعداد (اندريا ناجي2004) - قائمة ملاحظات أنماط الذكاء السبعة للبالغين أعدتها (نانسي فارس: Nancy :faris $(2004$

- قائمة الذكاء المتعددة إعداد (منال زكي الجندي : 2005) وقد أتفقت معظم الدر اسات على أن الذكاءات المتعددة تتحصر في : - الذكاء اللغوي- الذكاء المنطقي- الذكاء المكاني- الذكاء الحركي- الذكاء الأجتماعي- الذكاء الشخصي - الأكاء الموسيقي. وبناء على ذلك فقد اعتمدت الباحثة على الذكاءات التي أتفقت عليها الدراسات السابقة لتمثل أبعاد قائمة الذكاءات المتعددة للطالبة المعلمة. r - صياغة عبارات قائمة الأكاء ات المتعددة للطالبة المعلمة : بعد تحديد الأبعاد الأساسية للقائمة والمتمثلة في الذكاءات السبع تم صياغة (1 M ) عبارة موزعة على الذكاءات السبع روعي فيها : - أن تكون مناسبة للهدف المراد قياسه. - وضوح العبارات وسلامة الصياغة. 
ب - قائمة الأكاءات المتعددة للطالبة المعلمة في صورتها المبدئية مرفق ( (1): تم عرض القائمة على مجموعة من المحكمين في مجال علم النفس الرياضي مرفق (Y) لإبداء الرأى حول سلامة صياغة العبارات وإرتباط كل عبارة بالبعد الذي تتنمى اليه، وحذف أو تعديل أو إضافة أي عبارة يرونها مناسبة.

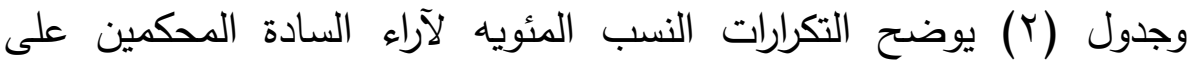
عبارات قائمه الذكاءات المتعددة للطالبة المعلمة.

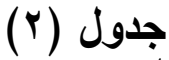

النسب المئويه لآراء المحكمين على عبارات قائمة الأكاء ات المتعددة للطالبة

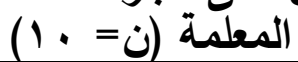

\begin{tabular}{|c|c|c|c|c|c|c|c|c|c|c|}
\hline \multicolumn{2}{|c|}{ غير موافز } & \multicolumn{2}{|c|}{ موافزة } & \multirow[t]{2}{*}{ م } & \multicolumn{2}{|c|}{ غير موافز } & \multicolumn{2}{|c|}{ موافزة } & \multirow[t]{2}{*}{ مم } & \multirow{2}{*}{ ألقائهاد } \\
\hline نسسبه. & تكرار & نسبه.\% & تكرار & & نسبه.٪ & تكرار & نسسبه٪\% & تكرار & & \\
\hline 1. & 1 & 9. & 9 & 11 & 1. & 1 & 9. & 9 & .1 & \\
\hline 1. & 1 & 9. & 9 & IT & $r$. & $r$ & V. & V &.$Y$ & \\
\hline ^. & $\wedge$ & r. & $r$ & $\pi$ & ^. & $\wedge$ & $r$. & r &.$r$ & \\
\hline r. & r & $\Lambda$. & $\wedge$ & $1 \leqslant$ & V. & V & r. & $r$ &.$\varepsilon$ & \\
\hline 1. & 1 & 9. & 9 & 10 & $r$. & r & A. & $\wedge$ & .0 & \\
\hline- & - & $1 \ldots$ & 1. & 17 & 1. & 1 & 9. & 9 & .7 & \\
\hline v. & V & r. & $r$ & IV & 1. & 1 & 9. & 9 &.$V$ & \\
\hline 7. & 7 & $\varepsilon$. & $\varepsilon$ & 11 & 0 . & 0 & 0 . & 0 & .1 & \\
\hline$\Lambda$. & $\Lambda$ & $r$. & $r$ & 19 & 7. & 7 & $\varepsilon$. & $\varepsilon$ & .9 & \\
\hline- & - & $1 \ldots$ & 1. & r. & r. & r & $\Lambda$. & $\wedge$ & 1. & \\
\hline r. & $r$ & $\vee$. & V & 1. & $r$. & r & ᄉ. & $\wedge$ & .1 & \\
\hline- & - & $1 \ldots$ & 1. & 11 & 0 . & 0 & 0 . & 0 &.$r$ & \\
\hline ^. & $\wedge$ & r. & $r$ & IT & - & - & $1 \ldots$ & 1. &.$r$ & \\
\hline- & - & $1 \ldots$ & 1. & $1 \pi$ & 1. & 1 & 9. & 9 &.$\varepsilon$ & \\
\hline V. & V & $r$. & $r$ & $1 \varepsilon$ & $r$. & r & ᄉ. & $\wedge$ & .0 & \\
\hline- & - & $1 \ldots$ & 1. & 10 & 1. & 1 & 9. & 9 & .7 & \\
\hline 7. & 7 & $\varepsilon$. & $\varepsilon$ & 17 & - & - & $1 \ldots$ & 1. &.$V$ & \\
\hline$r$. & $r$ & $\Lambda$. & $\Lambda$ & IV & $V$. & V & $r$. & $r$ & .1 & \\
\hline V. & V & r. & $r$ & 11 & $r$. & r & A. & $\wedge$ & .9 & \\
\hline$r$. & $r$ & ^. & $\wedge$ & 11 & $r$. & r & $\wedge$. & $\wedge$ & .1 & \\
\hline 7. & 7 & $\varepsilon$. & $\varepsilon$ & IT & 0 . & 0 & 0 . & 0 &.$r$ & \\
\hline 1. & 1 & 9. & 9 & $1 T$ & r. & $r$ & V. & V &.$r$ & \\
\hline$v$. & V & $r$. & $r$ & $1 \leqslant$ & $\wedge$. & $\wedge$ & $r$. & r &.$\Sigma$ & \\
\hline$r$. & r & ^. & $\Lambda$ & 10 & 1. & 1 & 9. & 9 & .0 & \\
\hline 1. & 1 & 9. & 9 & 17 & - & - & $1 \ldots$ & 1. & .7 & \\
\hline 1. & 1 & 9. & 9 & IV & 7. & 7 & $\varepsilon$. & $\varepsilon$ &.$v$ & \\
\hline
\end{tabular}


تابع جدول (r)

النسب المئويه لآراء المحكمين على عبارات قائمة الأكاء ات المتعددة للطالبة

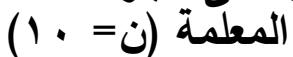

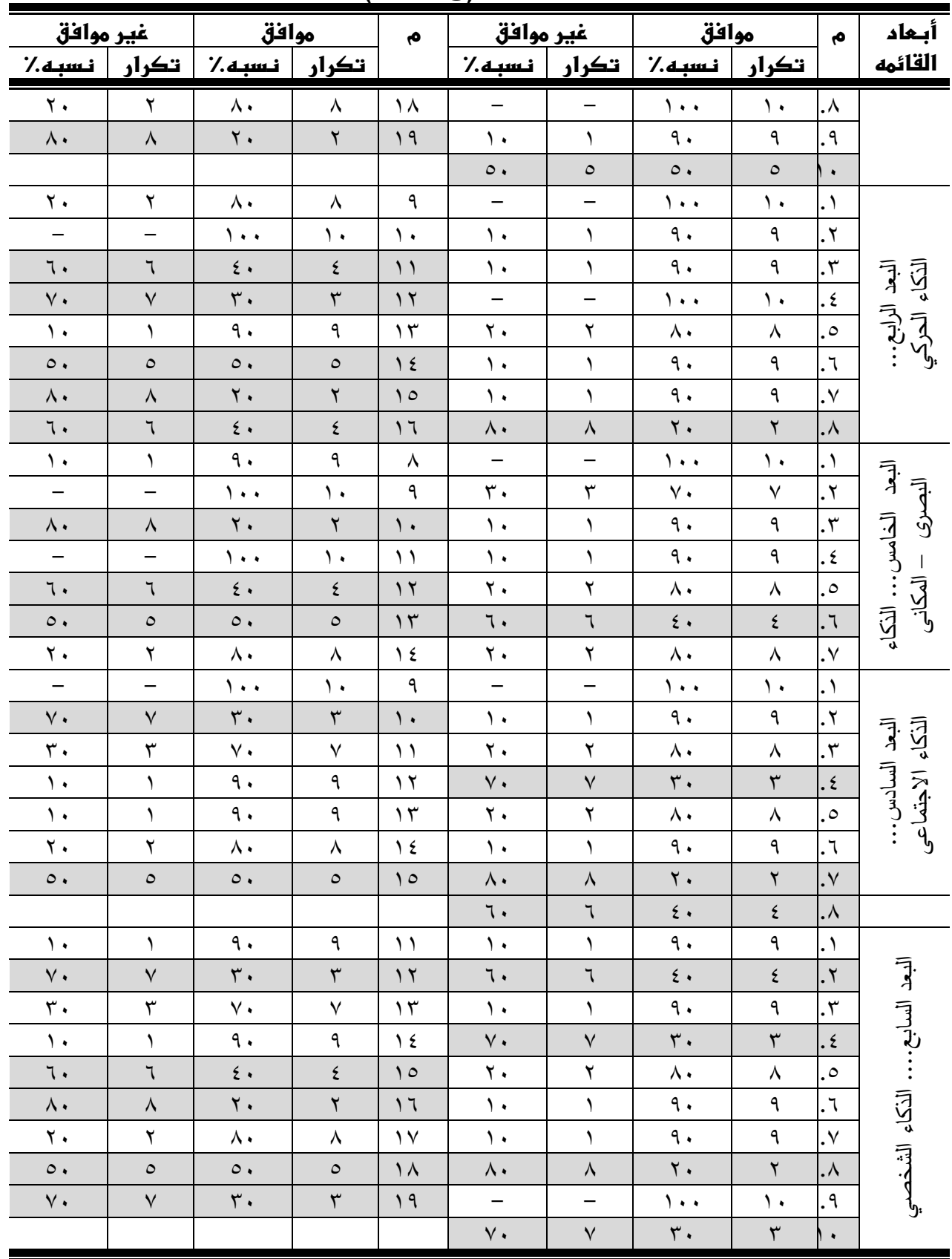


- إجماع المحكمين على مناسبة العبارات للأبعاد التي تتدرج تحتها. - حساب النسب المئويه لاتفاق المحكمين على عبارات القائمه. - تعديل صياغة بعض العبارات. - اعتمدت الباحثه على العبارات التي تراوحت نسبة اتفاق المحكمين عليها ما باتهات

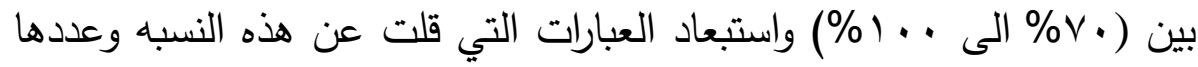

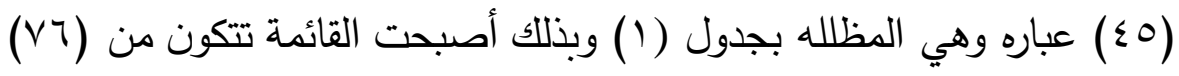

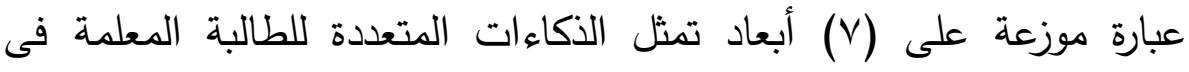

صورتها الاولية. ملحق (ب).

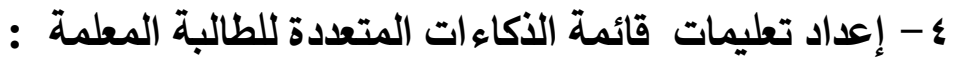

تضمنت التعليمات الإشارة الى عدم وجود إجابات صحيحة وأخرى خاطئة

$$
\text { وعدم ترك عبارة بدون الاجابة عليها. }
$$

ه- مفتاح تصحيح قائمة الأكاءات المتعددة للطالبة المعلمة في في صورته الاولية :

تم استخدام ميزان ثلاثي التقدير ووضع ثلاث استجابات امام كل عبارة (اوافق- الى حد ما- لا أوافق) ودرجتها (r- r- (1) للعبارات الايجابية، (1- r- r r اللعبارات السلبية وبذلك تكون الدرجة العظمى والصغرى للأبعاد

وللقائمة ككل كما يوضحها جدول (r)

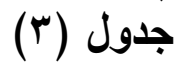

الارجة العظمى والصغرى لأبعاد قائمة الأكاءات المتعدده والقائمة ككل

\begin{tabular}{|c|c|c|}
\hline الدروة الصغرى & الدروة العظهم & أبـعاد قائمه الذكاءات المتعدده \\
\hline 14 & ry & البعد الاول.. الذكاءاللغوي (اللفظى) \\
\hline Ir & ry & البعد الثانى... الذكاءالمنطقي \\
\hline ir & ry & البعد الثالث.. الذكاء المكانى \\
\hline 1. & $r$. & البعد الرابع.. الذكاءالحركى \\
\hline 1. & $r$. & البعد الخامس.. الذكاءالأجتماعى \\
\hline 1. & $r$. & البعد السادس.. الذكاءالشخصى \\
\hline 1. & $r$. & البعد السابع.. الذكاء الموسيقي \\
\hline$\overline{V 7}$ & TYA & القائمه ككل \\
\hline
\end{tabular}

مجلة أسيوط لعلوم وفنون التربية الرياضية 


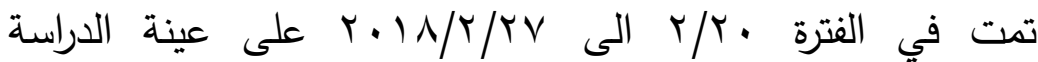
الأستطلاعية وقوامها ( • (ץ) طالبة من طالبات التدريب الميداني بكلية التربية

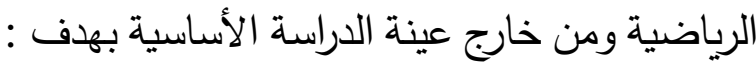
- حساب المعاملات العلمية لقائمة الأكاء ات المتعدده للطالبه المعلمهلة بوفية بكلية التربية الرباضية : ابلية أولا : صدق قائمة الأكاء ات المتعددة للطالبة المعلمة :

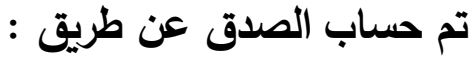

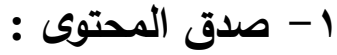

تم عرض قائمة الذكاءات المتعدده في صورتها الاولية متضمنه (VT) عباره مندرجه تحت الأبعاد السبع على المحكمين فى مجال علم النفس الرياضي

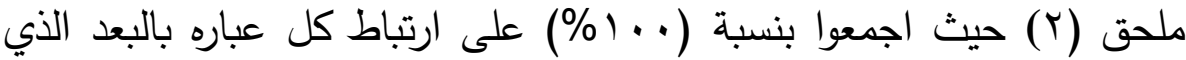

$$
\text { تندرج تحته. }
$$

r - الصدق التجريبي (صدق الاتساق الاخلي)

تم عن طريق إيجاد معامل الإرتباط بين درجة كل عبارة والدرجة الكلية للبعد

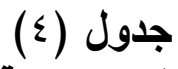

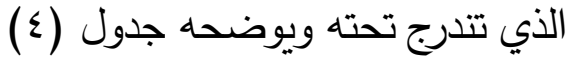

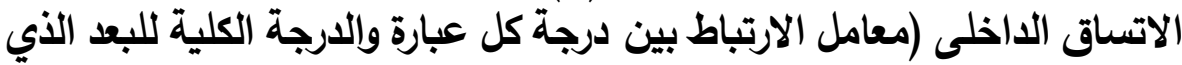

\begin{tabular}{|c|c|c|c|c|c|c|c|c|c|c|c|c|c|}
\hline \multicolumn{2}{|c|}{ الذكاء الشفصير } & \multicolumn{2}{|c|}{ الإبتماعي } & \multicolumn{2}{|c|}{ الذكاء البصرى } & \multicolumn{2}{|c|}{ الذكاء الهركي } & \multicolumn{2}{|c|}{ الذكاء الموسيقى } & \multicolumn{2}{|c|}{ الذكاء المنطقيي } & \multicolumn{2}{|c|}{ الذكاء اللغوير } \\
\hline | & العبارة & $\mid$ & العبارة & |لالارتباط| & |العبارة & $\begin{array}{c}\text { مالارتباط } \\
\text { معاط }\end{array}$ & العبارة & $\begin{array}{c}\text { J معالإ } \\
\text { J }\end{array}$ & العبارة & $\begin{array}{c}\text { معاراط } \\
\text { معباط }\end{array}$ & العبارة & 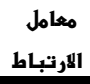 & رقمة \\
\hline..$v 17$ & 1 &. $.70 r$ & 1 & $. \wedge . \Sigma$ & 1 & $.7 r_{0}$ & 1 &. $.7 \%$ & 1 &.$V Y \varepsilon$ & 1 &. $.70 r$ & 1 \\
\hline ..vor & r & $\mid .7 r \Delta$ & r & .r^々 & r &. .709 & r & $.09 \xi$ & r &. .701 & r & . ror & r \\
\hline 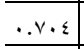 & $r$ & $.7 \leqslant 1$ & $r$ & $\therefore v v_{0}$ & $r$ & . . TAK & $r$ & . .rrq & $r$ &.$\wedge 1$. & $r$ &.$v 1 \varepsilon$ & $r$ \\
\hline. $\mathrm{VTA}$ & $\varepsilon$ & . .vтT & $\varepsilon$ & .VYr & $\varepsilon$ & $.7 \leqslant \mathrm{~V}$ & $\varepsilon$ & $.7 \leqslant r$ & $\varepsilon$ &. $.79 \varepsilon$ & $\varepsilon$ & . vor & $\varepsilon$ \\
\hline. .791 & 0 &. .111 & 。 & $. v \leqslant r$ & 0 & $.7 \mathrm{TH}$ & 0 &. .771 & 0 &. .217 & 。 & $.77 \varepsilon$ & 0 \\
\hline. $.7 \mathrm{TV}$ & 7 & . .vva & 7 & .011 & 7 & .0099 & 7 &.$v \varepsilon_{.}$ & 7 & $. . \vee \leqslant 1$ & 7 & .0997 & 7 \\
\hline..$v \cdot 0$ & v & .. $\leqslant 1 v$ & v & $.70 \leqslant$ & v & $. v \leqslant 1$ & v &..$V Y \Lambda$ & v & .794 & v &..$P V_{1}$ & v \\
\hline ... $\cdot r$ & $\wedge$ & $\mid . v \leqslant r$ & $\wedge$ &..$T r v$ & $\wedge$ & . . Tur & $\wedge$ &. .709 & $\wedge$ & ..817 & $\wedge$ &..$V T \varepsilon$ & $\wedge$ \\
\hline
\end{tabular}

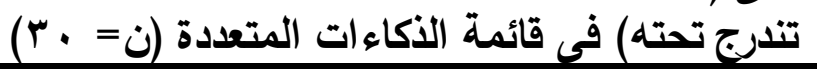




\section{تابع جدول (ء)}

الاتساق الداخلى (معامل الارتباط بين درجة كل عبارة والدرجة الكلية للبعد الذي

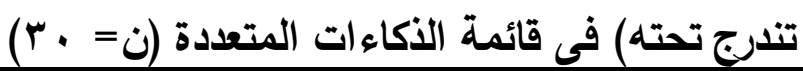

\begin{tabular}{|c|c|c|c|c|c|c|c|c|c|c|c|c|c|}
\hline \multicolumn{2}{|c|}{ الذكاء الشخصي } & \multicolumn{2}{|c|}{ الذكاء } & \multicolumn{2}{|c|}{ الذكاء البصرى } & \multicolumn{2}{|c|}{ الذكاء الهركي } & \multicolumn{2}{|c|}{ الذكاء الموسيقى } & \multicolumn{2}{|c|}{ الذكاء المنطقيي } & \multicolumn{2}{|c|}{ الذكاء اللغوي؟ } \\
\hline معامJ & | رقم & Jeماo & رقم & معامJ & رقم & 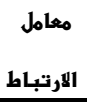 & رقم & معامل & رقم & معامل & العبارة & $\begin{array}{l}\text { Jolo } \\
\text { 1 }\end{array}$ & العبارة \\
\hline .VTr & 9 & .794 & 9 & $. . v \leqslant r$ & 9 & . vor & 9 & . & 9 & ת. & 9 & $\therefore$ VNo & 9 \\
\hline$\cdots v 1$. & 1. &.$v 71$ & 1. &..$\times 11$ & 1. & $\cdot v \cdot r$ & 1. & - & 1. & $\cdot . \Lambda \cdot r$ & 1. & $\cdot . \wedge \leq 7$ & 1. \\
\hline & & & & & & & &. .019 & 11 &. .091 & 11 & .700 & 11 \\
\hline & & & & & & & &. .74. & ir &..$T V Y$ & ir &..$T V T$ & ir \\
\hline
\end{tabular}

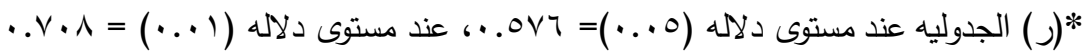

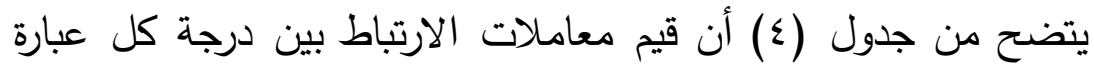

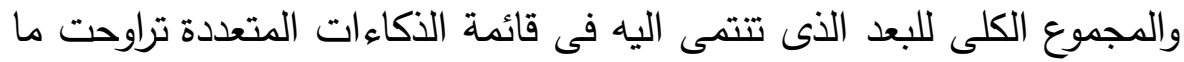

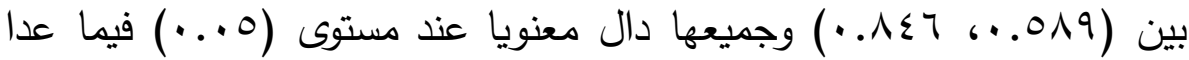

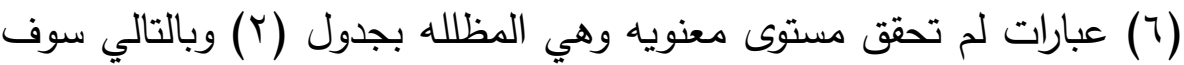
يتم حذفها، وهذه النتيجه تؤكد أن عبارات القائمه ترتبط بالأبعاد التى تتدرج تحتها ولذللك فهى تساهم فى بناء القائمه وتقيس ما وضعت من أجله ولذا فهى تتسم

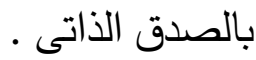

ثبات قائمة الأكاء ات المتعدده للطالبه المعلمه بكلية التربية الرياضية : تم حساب ثبات قائمة الذكاءات المتعدده عن طريق تطبيق القائمة على

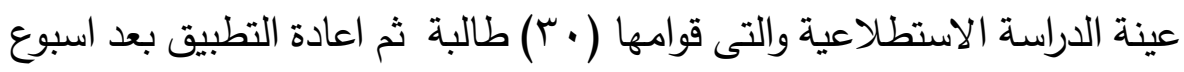

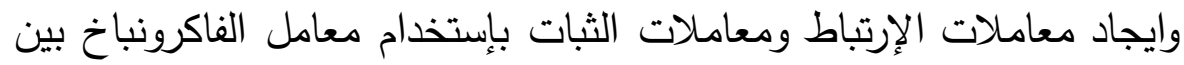

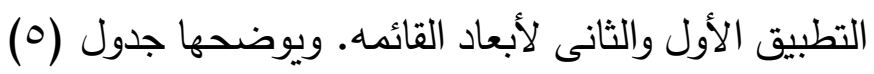


جدول (0)

معامل الارتباط ومعامل الثبات بين التطبيق الاول والتطبيق الثانى لمحاور

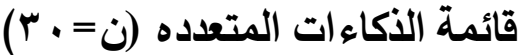

\begin{tabular}{|c|c|c|c|c|c|c|}
\hline \multirow{2}{*}{ الثباتل } & \multirow{2}{*}{ 1ل } & \multicolumn{2}{|c|}{ التطبيلزة الثنانـي } & \multicolumn{2}{|c|}{ 11لتطبئز الول } & \multirow{2}{*}{ 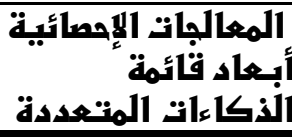 } \\
\hline & & $\varepsilon^{ \pm}$ & س س & $\varepsilon^{ \pm}$ & س س & \\
\hline. .1 & 1 & $0 . \wedge 7$ & Yo.. T & 0.41 & Y^. $\mid \leq$ & اللغوي (اللفظيل.. الذكاء \\
\hline$\cdot .1$ & $\because$ VOr & $\varepsilon . \wedge \vee$ & r^. $1 \leq$ & $\{.07$ & YT.TY & أض الذكاء \\
\hline. & r.VT & $0 . V V$ & T.IV & rז. & r & البعد الثي \\
\hline$\cdot$ & & $\varepsilon . .1$ & $0 . \Sigma Y$ & $r .10$ & TY.TY & . . الذكاء \\
\hline . . & & $\varepsilon .77$ & r & «.乏1 & $r \leq .07$ & ب... الذكاء \\
\hline$\cdot .117$ & $\because \vee 91$ & 0 & ro. $\leqslant r$ & $\varepsilon . \varepsilon \varepsilon$ & \& & (... الذكاء. \\
\hline$\because \vee 90$ & .710 & r & $r T . \varepsilon r$ & i & $r$ & ال اذكاء \\
\hline$\cdot . \wedge \leq \Gamma$ & אוד ר. & & 1117.87 & . & IVฯ. & قائمة الذكاءات \\
\hline
\end{tabular}

يتضح من جدول (0) أن قيم معاملات الارتباط بين التطبيق الاول

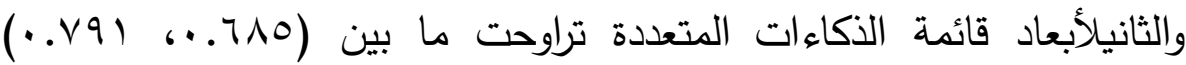

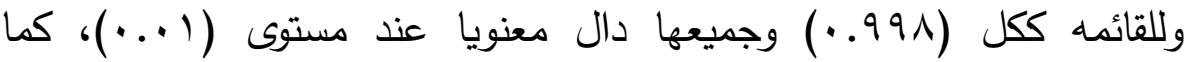

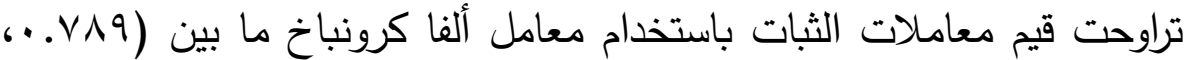

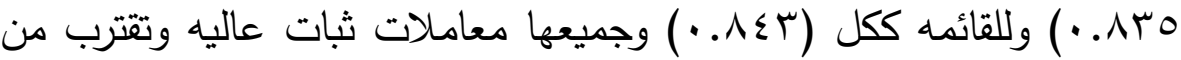

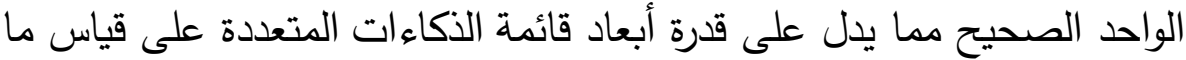
وضعت من أجله.

وبالتالي تكون قائمة الذكاءات المتعددة في صورتها النهائيه تشتمل على

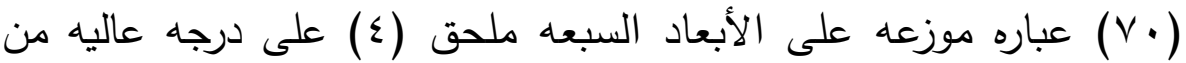
الصدق والثبات تئكد الثقه في النتائج التي يمكن الحصول عليها عند تطبيقها على عينة الدراسة الاساسيه. 
- النهايه العظمى والصغرى لأبعاد قائمة الاككاءات المتعددة للطالبة المعلمة

في صورتها النهائيه :ويوضحها جدول (7)

جدول (7) جول (7)

النهايه العظمى والصغرى لأبعاد قائمة الأكاءات المتعددة وللقائمة ككل

\begin{tabular}{|c|c|c|}
\hline النهابه الصغرى & النـهايه العظمه & أبـعاد قائمه الذكاءات المتعدده \\
\hline 11 & Tr & البعد الاول.. الذكاء اللغوي (اللفظي) \\
\hline 11 & 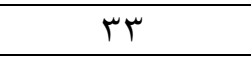 & البعد الثانى .. الذكاء المنطقى الرباضى \\
\hline 11 & rt & البعد الثالث.. الذكاء البصري المكانى \\
\hline 1. & $r$. & البعد الرابع.. الذكاء الحركى \\
\hline 9 & TV & البعد الخامس.. الذكاء الأجتماعى \\
\hline 9 & $r V$ & البعد السادس.. الذكاء الشخصى \\
\hline 9 & TV & البعد السابع.. الذكاء الموسيقي \\
\hline V. & r). & القائمه ككل \\
\hline
\end{tabular}

ب- بطاقة ملاحظة لتقييم الكفاءة التدريسية للطالبة المعلمة. ملحق (0) هي بطاقة موضوعة من قبل مكتب التدريب الميداني بقسم المنـاهج

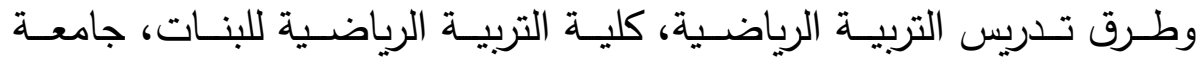
الإسكندرية، وتستخدم لقياس وتقيم الكفاءة التدريسية للطالبة المعلمة، في مادة التدريب الميداني، وتتكون من أربعـة أبعاد رئيسية هي تخطيط الدرس، تنئيذ الدرس، تقويم الدرس،الصفات الشخصـة والاجتماعة ومجموعها الكلى ( . . ( )

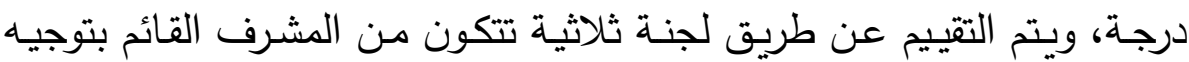

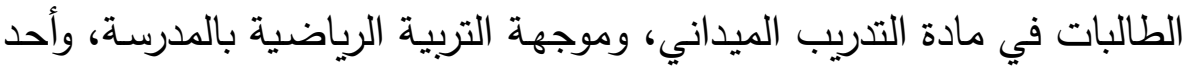

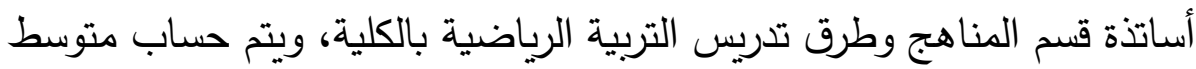

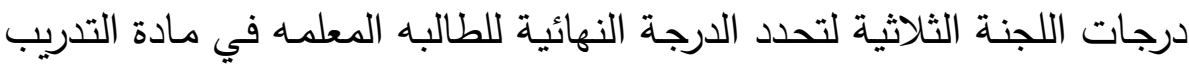
الميداني. الاراسة الأساسية:

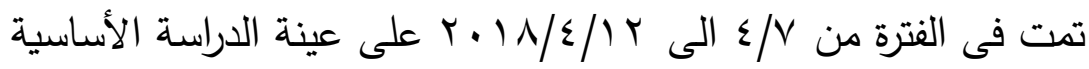
وقوامها (r) طالبه من طالبات الفرقة الرابعة شعبة تعليم بكلية التربية الرياضية للبنات جامعة الاسكندرية. 
- المعالجات الإحصائية: - -

- معامل الثبات"الفاكرونباخ".

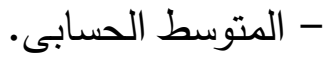

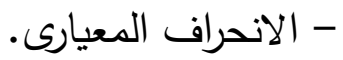

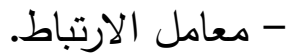

- الانحدار الخطي المتعدد.

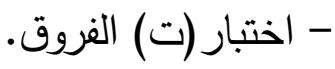

عرض ومناقشة النتائج :

سوف يتم عرض ومناقشة النتائج من خلال التحقق من فروض الدراسة

الفرض الأول: "تسهم الذكاءات المتعددة بنسب متباينة فى تفوق الطالبة المعلمة فى مادة التدريب الميدانى" للتحقق من صحة الفرض الاول تم استخدام معادلة

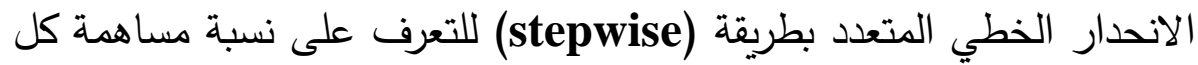
نوع من أنواع الذكاءات في تفوق الطالبه المعلمه في مادة التدريب الميداني

(v) ويوضحها جدول

جدول (v)

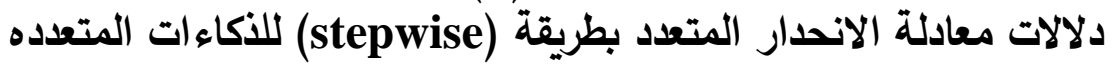

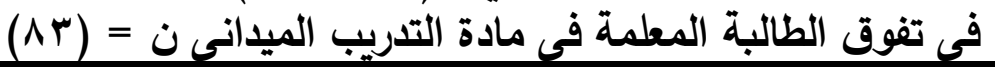

\begin{tabular}{|c|c|c|c|c|c|c|c|}
\hline المعباربي & قيهةة & قيهمة & 1النمهامل & المهيساهوبة & 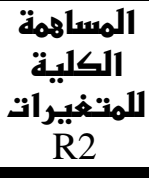 & 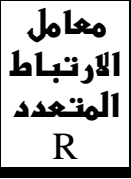 & دلالانت التنبـوّة \\
\hline.$Y \backslash \Lambda$ & 00.571 & $7.7 \vee \wedge$ & $1.501-$ & $\varepsilon 0 . V$ &. .5071 & . . Art & الذكاء البصري المكاني \\
\hline$. .1 \times 0$ & $\Sigma \Lambda . \leqslant \wedge \vee$ & $\varepsilon . \vee \wedge \varepsilon$ & $.+471-$ & $11 . r$ &. .877 & $\cdot . \wedge \wedge \vee$ & الذكاء الحركى \\
\hline$\ldots 19$ & 74.991 & r.s.1 & $. .7 \leq-$ & $1 \cdot .7$ & $\cdot . \wedge 7 \varepsilon$ &. .941 & الذكاء الشخصي \\
\hline..$M V$ & 01.717 & Y.M.M & $. .7 r-$ & 9.7 & $\cdot . v \cdot 9$ & $\cdot .9 \leq V$ & الأكاء الأجتماعى \\
\hline. .119 & $74.90 \pi$ & 7.77. &. .V9Y- & A.1 & .1001 & $\because \vee \wedge$. & الذكاء اللغوي (اللفظى) \\
\hline$. \wedge 9 \leqslant$ & OY.ITO & $0 . Y \leq 1$ &. $.7 \wedge \mathrm{V}$ & 0.1 & $.0 Y 0$ & $\cdot . \wedge \vee 0$ & الذكاء الموسيقي \\
\hline.$Y T Y$ & $71 . r Y q$ & Y.Tะ. &. .009 & $\varepsilon . Y$ & ת &. .94. & الذكاء المنطقي الرياض \\
\hline \multicolumn{7}{|c|}{0.17.} & قيمة القاطع \\
\hline
\end{tabular}

يتضح من جدول (V) والخاص بدلالات الانحدار المتعدد للذكاءات

المتعدده ونسب مساهمه كل ذكاء فى تقوق الطالبة المعلمة فى مادة التدريب

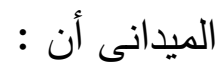




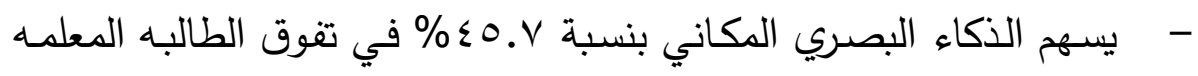

$$
\text { في مادة التدريب الميداني. }
$$

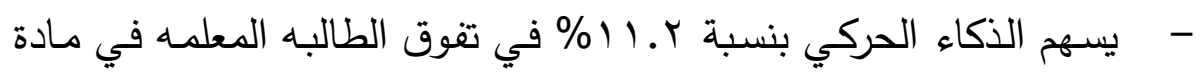

$$
\text { التدريب الميداني. }
$$

- يسهم الذكاء الشخصي بنسبة 7 . • 1\% في تفوق الطالبه المعلمه في مادة

$$
\text { التدريب الميداني. }
$$

- - يسهم الذكاء الأجتماعي بنسبة 7 ـ9 في تفوق الطالبه المعلمه في مادة

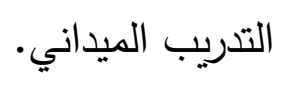

- - يسهم الذكاء اللغوي (اللفظي) بنسبة ا. 1 \% في تفوق الطالبه المعلمه في

$$
\text { مادة التتريب الميداني. }
$$

- - يسهم الذكاء الموسيقي بنسبة ^.0 \% في تفوق الطالبه المعلمه في مادة

$$
\text { التدريب الميداني. }
$$

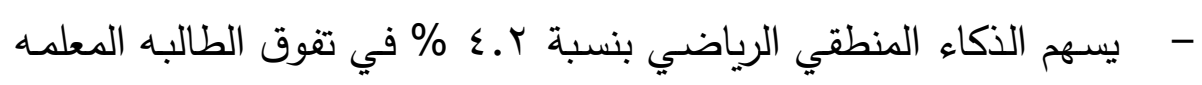

$$
\text { في مادة التدريب الميداني. }
$$

ومجموع الذكاءات المتعدده جميعها تسهم فى تفوق الطالبة المعلمة فى

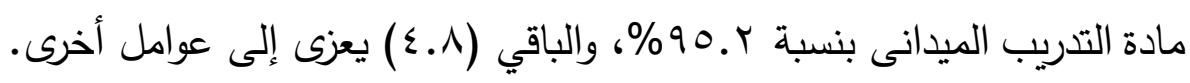

وتتفق نتائج هذا الفرض مـ نتائج دراسـة كل من (المهدى الذويب:

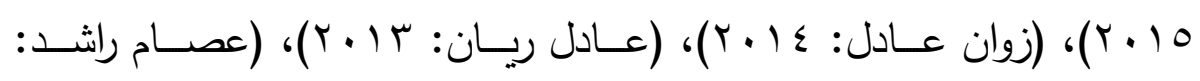

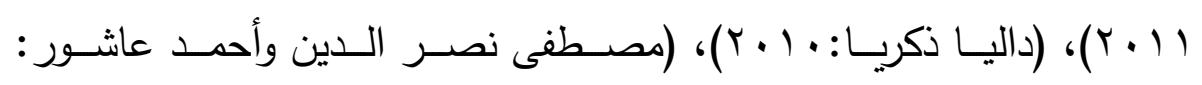

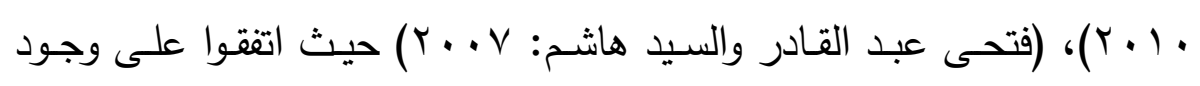
الذكاءات المتعددة بنسب متفاوته. وتتفق تلك النتائج مع ما أشار اليه (حمدان

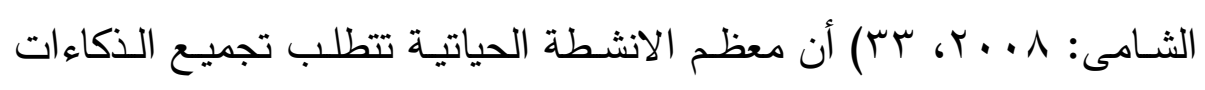
المتعددة الموجودة لدى الافراد بدرجات متفاوتة فقد يكون لدى البعض ذكاء قوى النى

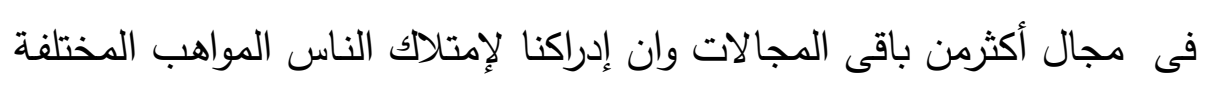

\section{مجلة أسيوط لعلوم وفنون التربية الرياضية}


تجعلنـا نقبل بأن كل شخص لديه شئ قيم يعرضـه وكلنـا نمتلك القدرة التى تمكننا من تزويد مواهبنا.

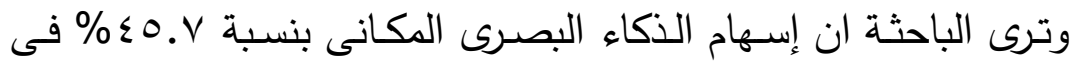
تفوق الطالبـة المعلمـة يعتبر نتيجـة منطقيـة حيث يوضـح (طـارق بدر الدين

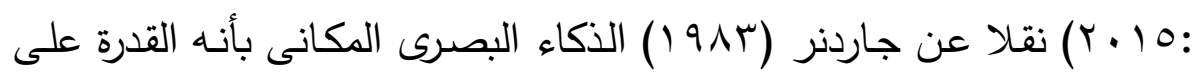
رؤية الكون على نحو دقيق وإدراك المعلومات البصرية والمكانية، والتفكير فى لهى

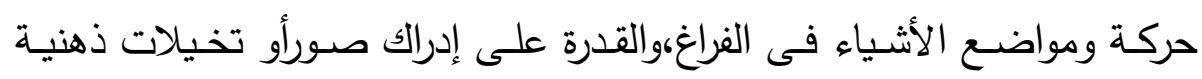

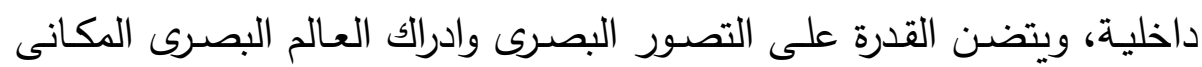

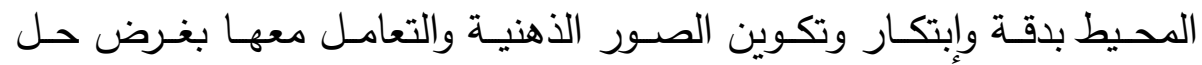
المشكلات أو إجراء التعديلات وإعاده إنشاء التصورات الآولية.

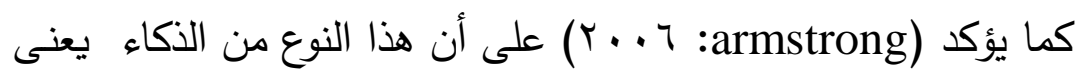
القدرة علي إدراك العالم المكانى بصريا بصورة دقيقة والقدرة على تصور المكان النسبى للاشياء في الفراغ. وترى الباحثة ان معظم الأنشطة الرياضية تتطلب قدرا كبيرا من الذكاء البصـرى المكانى والطالبة المعلمة تحتاج لهذا النوع من الذكاء حيث تحتاج للوعى بأجزاء الجسم فى الفراغ لتتمكن من آداء الحركات التى يقوم بتدريسها

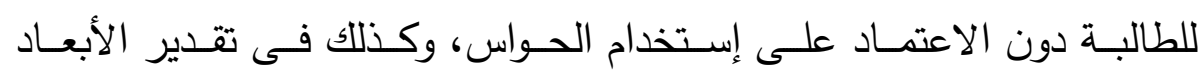
والاتجاهات، وتحديد المسافات والتحكم الصحيح بالجسم أثناء الآداء الحركى.

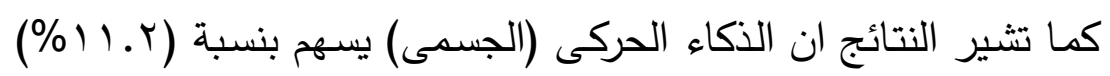

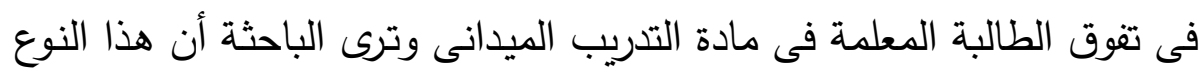

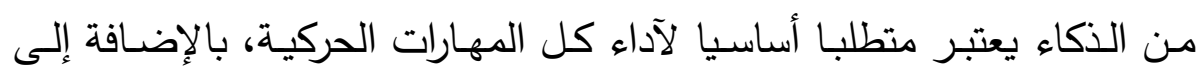
مساهمته فى نجاح وسرعة تعلم وآداء المهارات الحركية فهو يعنى قدرة الفرد على إستخدام قدراته العقلية ارتباطا مع حركات جسمه ككل للتعبير عن الأفكار والمشاعر او تحريكه على أنغام موسيقية وهذا الذكاء يضم مهارات محددة مثل إنبات حركات 
التوازن، القـوة، المرونـة، السـرعة، الاحسـاس بحركـة الجسـم ووضـعه والقـدرة اللمسية والجسمية الحركية الفائقة.

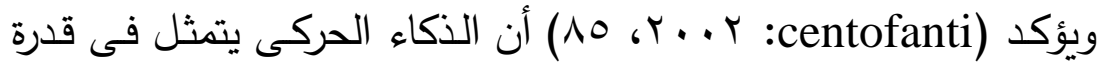
الفرد على إستخدام قدراته العقليه فى تتسيق حركاته الجسدية للتعبير عن افكاره ومشاعره عن طريق العروض واستخدام لغة الجسم واشـاراته بدقة والقدرة على إلى التمثيل والتقليد واستخدام الادوات بمهارة ويتضمن هذا الذكاء الاحساس بحركة الجسم أى أن هذا النوع من الذكاء جاء ليتحدى الاعتقاد السائد بان النشاطين العقلى والجسمى غير مرتبطين. وتـرى الباحثـة ان الطالبـة المعلمـة تقـوم بـآداء العديـد مـن التـدريبات والمهارات أمسام التلاميذ والقيام بمثل هذه المهارات يتطلب نوعـا مـن الذكاء الحركى حيث ان التميز فى سـرعة تغير إتجاه الجسم والتغيير المفاجئ فى حركاته أثناء الآداء الحركى الرياضسى يعد من أهم خصـائص ومكونات الذكاء الحركى للطالبة المعلمة. وتتفق ذللك مع نتائج دراسة (ابتسام فارس: ج . . ب) التى أكدت على أن الذكاء الحركى له أهمتهالتعليمية اذ يعتمد عليه المعلم فى الأنشطة التى تحتاج الى إستخدام المعالجات الواقعية لتشكيل المفاهيم عند التلميذ.. وتتفق تلك النتائج مـع نتائج دراسـة (داليا زكريـا: • ( • ب) التى اسفرت عن ان نسق الذكاءات المتعددة للاعبى الانشطة الرياضية قيد الدراسـة على الترتيب التالى الذكاء الحركى يليه الذكاء البصرى. كما تشير النتائج الى أن الذكاء الثخصى يحتل المكانة الثالثة فى تفوق الطالبة المعلمة فى مادة التدريب الميدانى حيث يسهم بنسبة (7 . • (\%) ويعتبر الذكاء الشخصسى من الذكاءات التى لابد ان تتميز بها الطالبه المعلمـه حيث تكمن الاهميـة العلمية لهذا الذكاء فى نظريـة الذكاءات المتعددة فـى انهه يقدم مجموعة من القدرات والإستراتيجيات والأنشطة والأدوات التى يمكن أن تستخدم

\section{مجالة أسيوط لعلوم وفنون التربية الرياضية}


فى قدرة الطالبة المعلمة على التحكم فى الحصـة والقدرة على حسن التصرف فى المواقف التى تواجهها عند الغضب وفهم مشاعر وأحاسيس التلاميذ وإجادة التعبيرعن المشـاعر لفظيا وشفويا ومعرفة نقاط القوة والضـف كما يجب ان تتصف بالثقة بالنفس والقدرة على حل المشكلات والتحكم الانفعالى فى المواقف

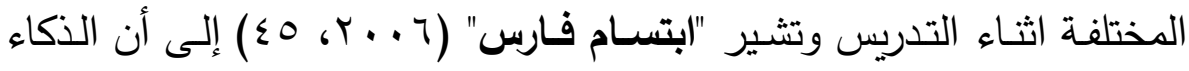
الشخصى لله دور كبير فى نجاح الفرد فى حياته العملية لانه يمكنه من إتخاذ القرارات التى تتناسب مع قدراته وتمييز الفروق الفردية بين الافراد.

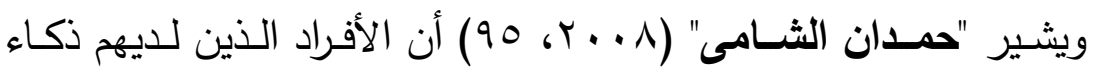
شخصى يتسمون دائما بالتخيل والصبر وضبط النفس والطموح واحترام الذات والعمل بكفاءة.

وترى الباحثة أن تفوق الطالبة المعلمة فى التدريس يتطلب قدرا كبيرا من الذكاء الشخصى الذى يساعدها على إسترجاع الخبرات السابقة التى سبق ان اكتسبتها فى مختلف مواقف التعلم والتدريب كذلك القدرة على اتخـاذ القرار السليم فى التوقيت المناسب. كما تشـير النتائج الى أن الذكاء الإجتمـاعى يحتل المكانـة الرابعـة فى في تفوق الطالبة المعلمـة حيث تسـهم بنسبة (7.9\%) ويعرف "حمـان الثـامى"

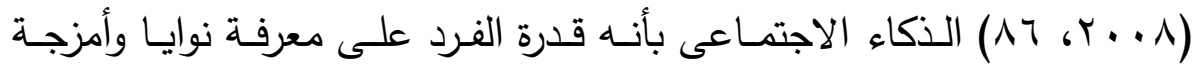
ودوافع وشعور وأحاسيس وسلوك ورغبات وإهتمامات وحالة الآخرين النفسية كما انه القدرة على التعامل مع الاخرين بشكل مؤثر وفعال ويظهر فى صورة تكوين علاقات وصداقات ونجاح فى المشاركة الاجتماعية بشكل جيد وملحوظ. وتـرى الباحثـة مـن خـلال ماسـبق ان الـذكاء الاجتمــاعى يعتبـر مـن

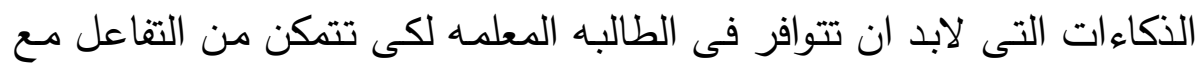
التلاميذ بشكل نشط وفعـال وتتمكن مـن معرفـة رغباتهم واحتياجتهم وميولهم والقدرة على تكوين علاقات اجتماعية معهم فنجاح الطالبه المعلمه يحتاج الى رعلى رعن 
هذا النوع من الذكاء بدرجة عاليه حيث يشير (طارق بدر الدين :0 1 ب أن أن هذا النوع من الذكاء يظهر بوضوح لدى المعلم الناجح من أجل تحقيق الهدف الذى يعتمـد السى حد كبيـر على فهم مشـاعر المتعلمين وإنفعـالاتهم وتفسـير سلوكياتهم وتحمل الضغوط والمصاعب بالاضافة الى التواصل الاجتماعى مع الزملاء.

وتتفق تلك النتائج مع ما أشـارت اليه نتائج دراسـة (المهدى عبد السـلام: 10 تخصص التدريب.

كما يتضح من الجدول رقم V) أن نسبة اسهام الذكاء اللغوي (اللفظي) بلغت (1) (1\%) وتري الباحثة ان الذكاء اللغوي هو قدرة الطالبة المعلمة علي التعبير بكل دقة عن المواقف والأشياء،والقدرة علي توصيل المعلومـة، وترجمة ما يجول بفكرها بطريقة صحيحة، فالطالبة التي تتميز بهذا النوع من الذكاء لديها القدرة علي وصف وشرح الحركات والتمرينات الرياضية شفهيا وصفا دقيقا يسهل علي المتعلم تطبيقها، بالاضـافة الي انها تتمتع بقدرة علي كتابة الدرس بكل محتوياته بشكل جيد ومميز كما تستطيع القيام بشرح المهارات المتعلمـة شرح جيد،ويتفق في ذلك (طارق بدر الدين :0 10 ب) أن اللغة هي أهم ما يميز

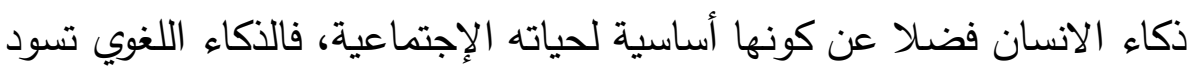
فيه اللغـة والحساسية للأصسوات والمعاني والافراد الذين يتمتعون بهذا الذكاء يكون لديهم نمو مرتفع في مكونات اللغة والمهارات الحسية كذللك للديهم قوة عالية علي معالجة اللغة واستخدام الكلام للتعبير عن النفس بالمخاطبة او كآداه للتواصل مع الاخرين. لذلك فأن هؤلاء الافراد يتميزون في مجال التعليم وغيره من المجالات مثل الصحافة والاذاعة. وتري الباحثـة ان الـذكاء اللغـوي يلعـب دورا هامـا فـي تفـوق الطالبـه المعلمه لما يجب ان تقوم به في حصـة التربية الرياضية من القاءها للتعليمات

\section{مجالة أسيوط لعلوم وفنون التربية الرياضية}


وشرحها للمهارات المتعلمة والتدريبات وقدرتها علي كتابة الدرس واهدافه بلغة سليمة، بالأضافة الي قدرتها علي التواصل مع التلاميذ خلال مواقف التعلم.

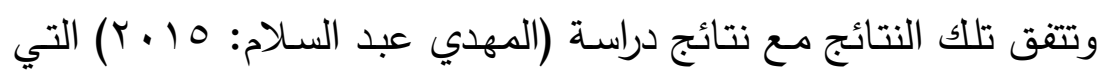

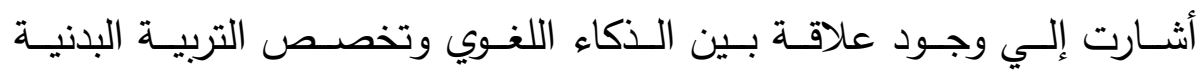
(التدريس) (التسات

كما تشير النتائج ايضا الي اسهام الذكاء الموسيقي بنسبة (1.0\%) في

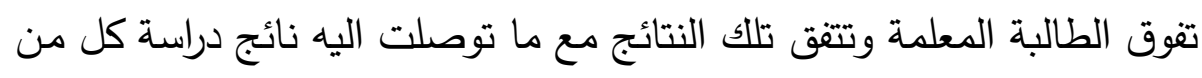

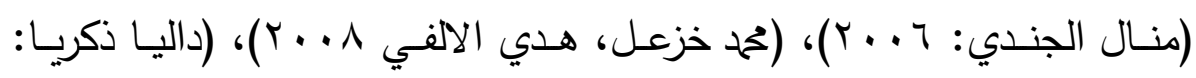

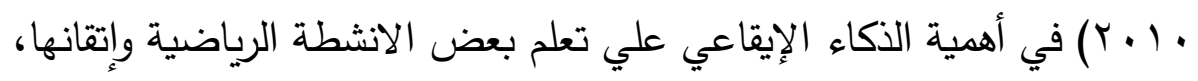

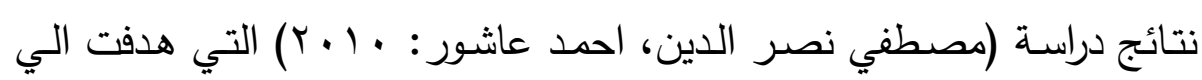
التعرف علي الذكاءات المتعددة ونسبة مساهمة كل منها في التحصيل المعرف ومستوي آداء بعض المهارات الاساسية في كرة السلة، وتوصلت النتائج الي ان الذكاء اللغوي مـن الذكاءات المسـهمة في درجـة التحصيل المعرفي ومستوي الاداء.

ويشير "طارق بـر الدين" (0 1 ـ ب) الى أن هناك العديد من الأنشطة تحتاج لهذا النوع من الذكاء بصسورة كبيرة لإستخدامه في تطوير إيقاع الفرد

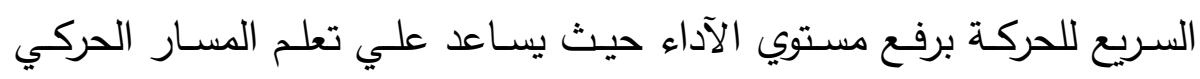

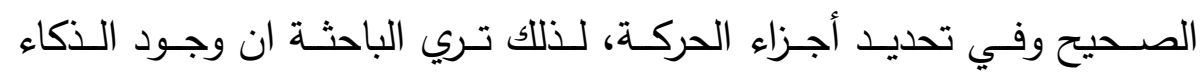
الموسيقي للطالبة المعلمة يعتبر متطلبا هاما من متطلبات التفوق حيث يمكنها

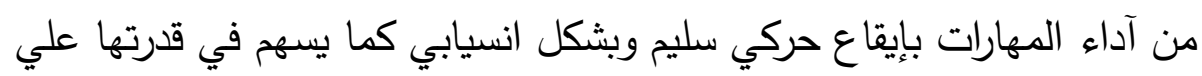
إبتكار حركات تتماشي مع الموسيقي عند آداء العروض الرياضية.

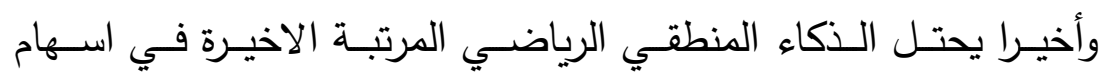
الذكاءات المتعددة في تفوق الطالبه المعلمه بنسبة (ץ. ؟٪\%) وتتفق هذه النتائج

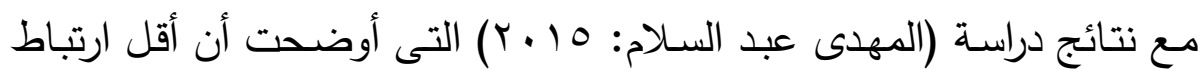


ظهر بين الذكاء المنطقى الرياضى وتخصص التدريب الرياضى، كما أظهرت

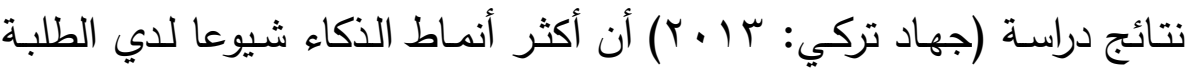

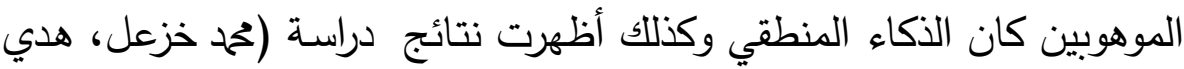

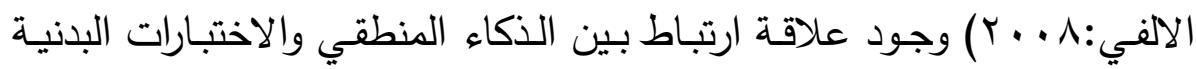

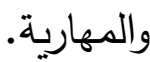

وتري الباحثة ان هذا النوع من الذكاءات تقل نسبة اسهامه في تفوق

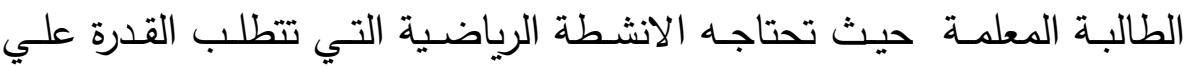

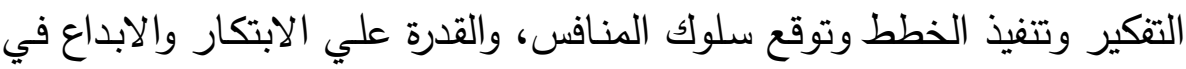

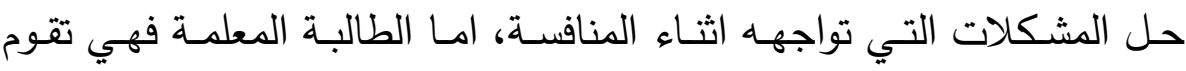

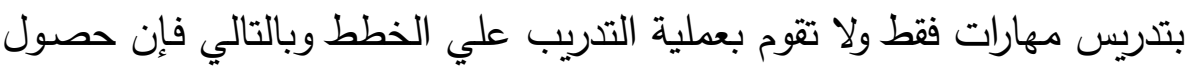

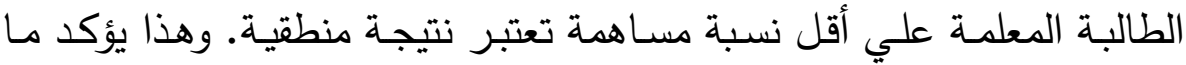

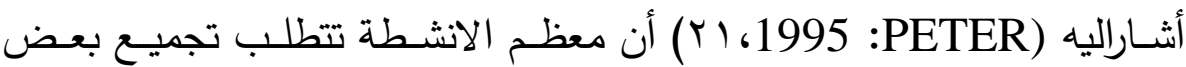

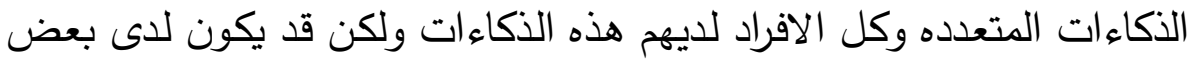
الافراد ذكاء قوى فى مجال معين ولكن ليس فى كل المجالات. وهذه النتيجة تؤكد صحة الفرض الأول للبحث. الفرض الثاني: "يكن التتبؤ بدرجة الطالبة المعلمة فى مادة التدريب

الميدانى بمعلومية الذكاءات المتعددة لديها."

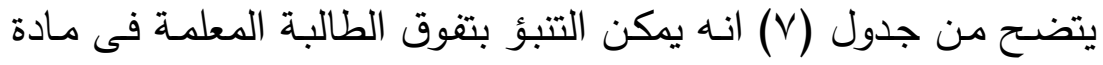
التدريب الميدانى بمعلومية الذكاءات المتعدده من خلال المعادله التاليه :

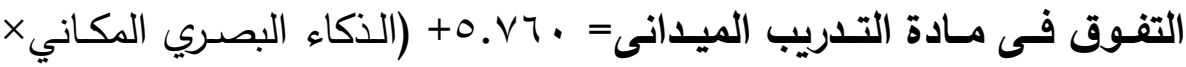

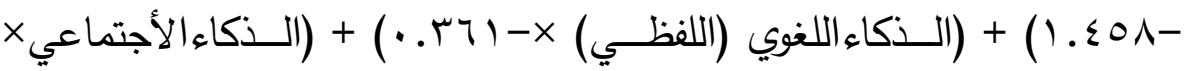

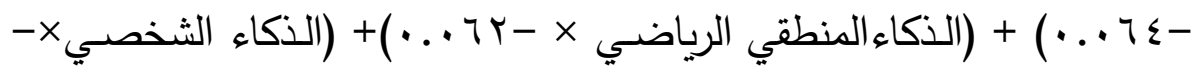

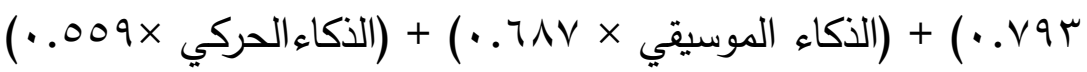


كما أن جميع المتغيرات الإحصـائية المؤهلة لتفوق الطالبة المعلمة فى مادة التدريب الميدانى بمعلوميـة الذكاءات المتعدده تؤكد فعالية المعادلة في

\section{الاستخلاصات :}

من خلال مناقشة النتائج امكن التوصل للاستخلاصات التالية : ا - يسهم الذكاء البصـري المكاني بنسبة V.0٪\% في تفوق الطالبه المعلمـه

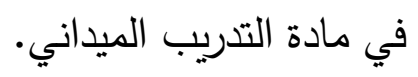

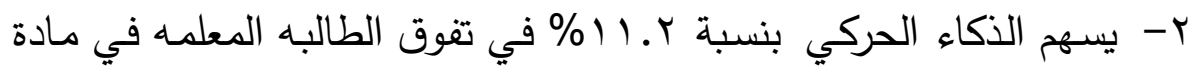

$$
\text { التدريب الميداني. }
$$

ب- يسهم الذكاء الشخصي بنسبة 7 . . 1\% في تفوق الطالبه المعلمه في مادة

$$
\text { التدريب الميداني. }
$$

ع - يسهم الذكاء الأجتماعي بنسبة 7.9\% في تفوق الطالبه المعلمه في مادة

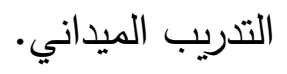

ه- يسهم الذكاء اللغوي (اللفظي) بنسبة ـ1\% في تفوق الطالبه المعلمه في

$$
\text { مادة التدريب الميداني. }
$$

ج- يسهم الذكاء الموسيقي بنسبة ^.0 \% م في تفوق الطالبه المعلمه في مادة

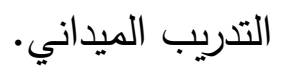

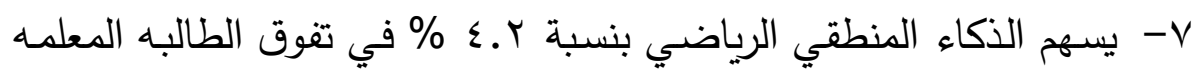

$$
\text { في مادة التدريب الميداني. }
$$

^- يمكن التتبؤ بدرجة الطالبة المعلمـة في مـادة التدريب الميدانى بمعلوميـة

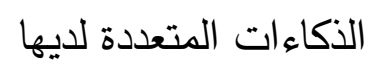

ثانيا التوصيات :

انطلاقا من نتائج البحث توصي الباحثة بما يلى :

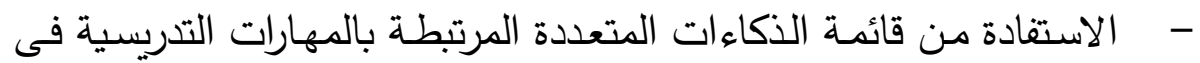
انتقاء الطالبة المعلمة بشعة تعليم. 
- وضـع برامج لتطوير الذكاءات التـى تحتاجها الطالبة المعلمة من اجل

$$
\text { التفوق فى التدريس. }
$$

- - توعيـة القـائمين بالتدريس على أهميـة نظريـة الذكاءات المتعددة وكيفيـة

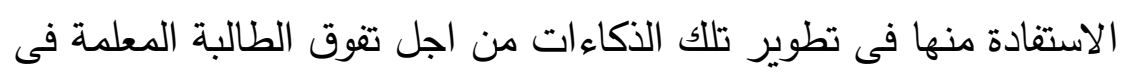

$$
\text { التدريس. }
$$

\section{$(($ r}

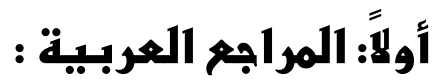

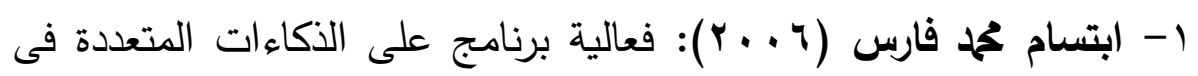

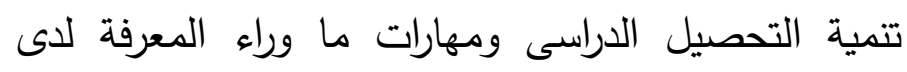

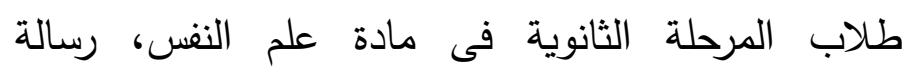

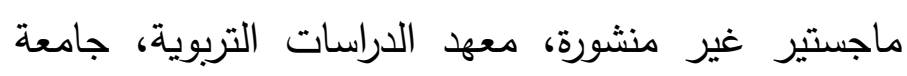
القاهرة.

ץ- أحمد عاشور (99V (19): فاعلية إستخدام اسلوب التطبيق بتوجيه الأقران على بعض الصفات البدنية والمهارية للمبتدئين فى كرة

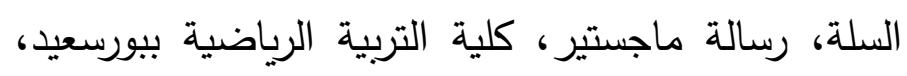
جامعة قناة السويس رسالة ماجسي

r- المهلى عبد السلام الذويب (10 + ب): الذكاءات المتعددة كمؤشر لإختيار التخصص الاكاديمى لطلاب كلية التربية البدنية وعلوم

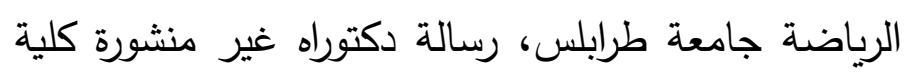
التربية الرياضية للبنات، جامعة الاسكندرية

ع- جيهان أبو راشد العمران (ه . . ץ): الذكاءات المتعددة للطلبة البحرنيين

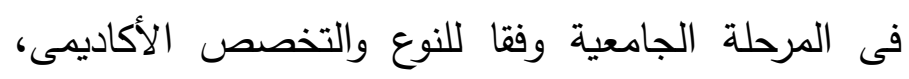

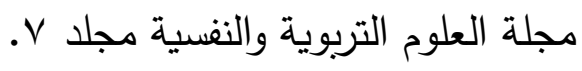




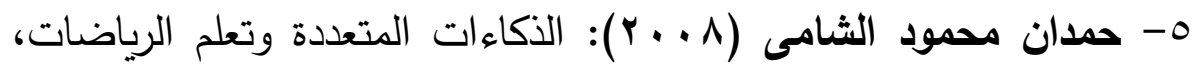
مكتبة الانجلو المصرية، طاه، القاهرة.

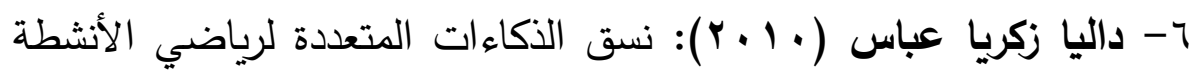
الفردية والجماعية، رسالة دكتوراه غير منشورة، كلية التربية الرياضية للبنات، جامعة الاسكندرية.

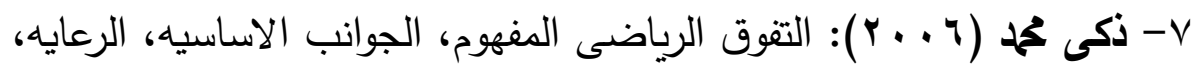
الانتقاء، المكتبة المصرية، لوران، الاسكندرية.

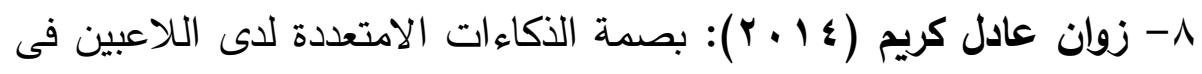

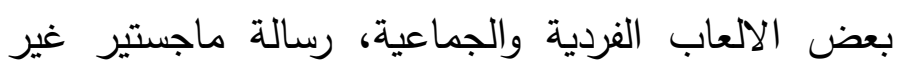

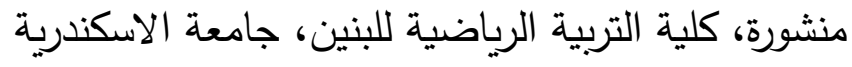

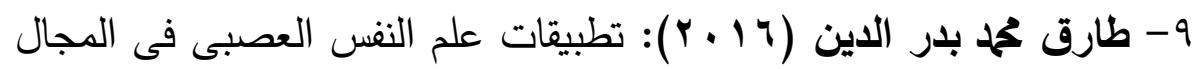
الرياضى، دار الفكر العربى، القاهرة.

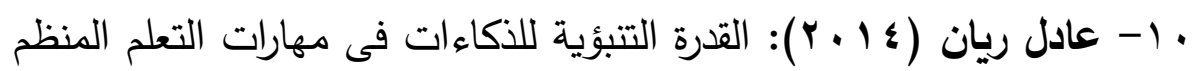

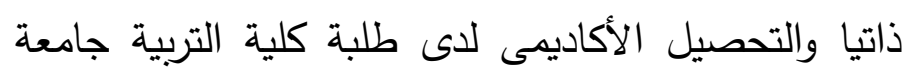

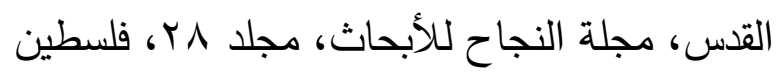
11- عصام راشد (11 ( ب): مستويات الذكاء المتعدد لدى تلاميذ المرحلة

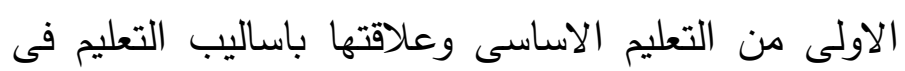

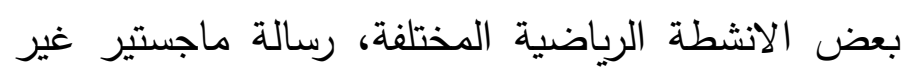
منشورة، كلية التربية الرياضية للبنين، جامعة الأسكندرية.

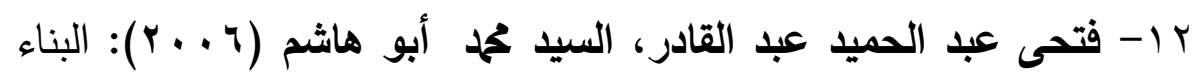
العاملى للذكاء فى ضوء تصنيف جاردنر وعلاقته بكل من

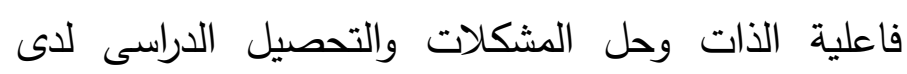
طلاب الجامعة، مجلة كلية التربية، جامعة الزقازيق.

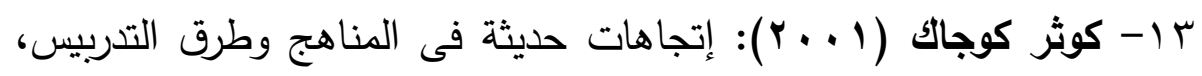
الطبعة الثانية، مكتبة عالم الكتب، القاهرة. 
ع ا- عثمان على (Y . . r): المعلم من الواجب الوظيفى الى الواجب

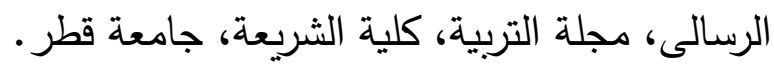

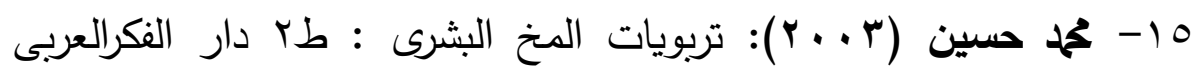
للطبع والنشر ، عمان.

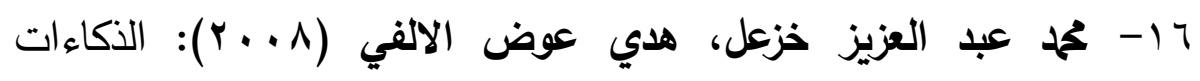
المتعددة وعلاقتها بإختبارات القبول لطلاب كلية التربية الرياضية للبنات بالاسكندرية، مجلة عالم التربية المؤسسة العربية للاستشارات العلمية وتتمية الموارد البشرية للتعاون العلمى مع رابطة التربية الحديثة، القاهرة.

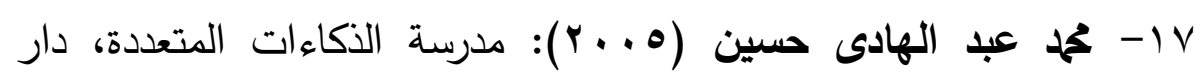
الكتاب الجامعى، غزة، فلسطين.

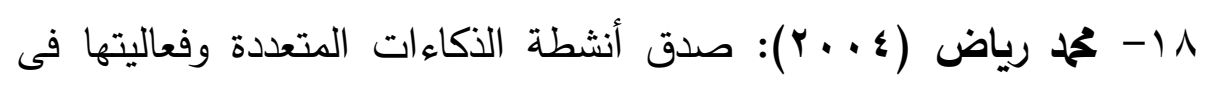
إكتشاف الموهوبين بالصف الخامس الإبتدائى، المجلة العلمية كلية التربية، جامعة أسيوط.

9 1 - محمود عصمت (؟ . . ץ): كفاءة بعض أنشطة نظرية الذكاءات المتعددة فى إكتثاف الموهوبين رياضيا، المجلة العلمية لكلية التربية البدنية والرياضية، جامعة المنصورة.

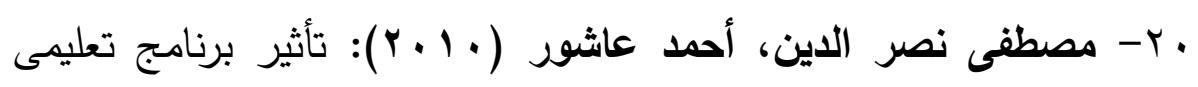

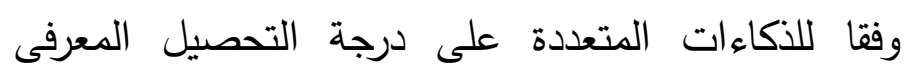
ومستوى آداء بعض المهارات الأساسية للمبتدئين فى كرة

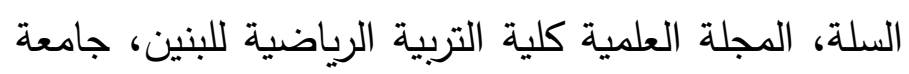
الأسكندرية.

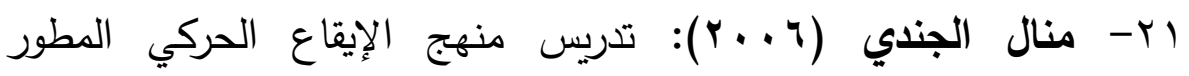

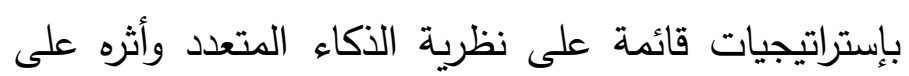


نواتج التعلم، رسالة دكتوراه غير منشورة، كلية التربية الرياضية للبنات، جامعة الإسكندرية.

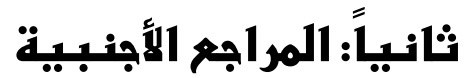

22- Ander Nagni (2004): Multiple IntelligencesQuestionnaire(online) Available: www. It is - Einstein.Roam. It.Arlicolol. Estattel giorale. him

23- Armstrong,j: Multiple Intelligences In The Classroom $3^{\text {rd }}$ Edition ,2006.

24- Cheekely, K.:(1997): The First Seven -And The Eight , A Conversation With Howard Gardner, Educational Leadership Vol. 55, No.1. September.

25- Centofanti, M: Difference among kindergartens in learning the alphabet using tactual kinesthetic multiple techuniversity, diss, abs, int, no $11,2002$.

26- Douglas, N.(2000) : Multiple intelligences test,

Available at :http://www.nedpord.com/ niall -stuff/intelligence-test.html

27- Gardner (2002): Multiple intelligences and Education Available www.infed.org/Thinkers/ gardner. htm 28- Hirschhorn,Douglas, Kamin (2000): "the relationship between emotional intelligence and performance statistics of NCAA division 1 caliber baseball player " south - Connecticut 
-state University -Dissertation abstracts international page 1691

29- Hoer, Thomas R. (1998): In Barnhardt, Resgis. Et Sl.,eds "Using multiple intelligences for students and faculty success ", Curricula leadership, Rethionking school for $21^{\text {st }}$ century, New jersy : Hampton Press, inc.

30- Ivanco.J. (1998): What are my learning Strengths ? Available at://www.snow.utronto.ca/courses/mitest.html

31- Ozdener.n\&Ozcoban : A 2004 project based learning mode effectiveness on computer courses and multiple intelligence theory education: theory practice vol.(4),no.(1),pp.146-170.

32- Solomon, peart G, (1998): The curriculum bridge, from standards to actual classroom practice Galifornia ; crownpress, Inc. 